LBL-36088

UC-600

\title{
Optimizing Multiphase Aquifer Remediation Using ITOUGH2
}

\author{
S. Finsterle and K. Pruess \\ Earth Sciences Division \\ Lawrence Berkeley Laboratory \\ University of California \\ Berkeley, CA 94720
}

June 1994

This work was supported by the WIPP project, Sandia National Laboratories, under Document No. 129847, and by U.S. Department of Energy, under contract DE-AC03-76SF00098. 
(28) 


\section{DISCLAIMER}

This report was prepared as an account of work sponsored by an agency of the United States Government. Neither the United States Government nor any agency thereof, nor any of their employees, make any warranty, express or implied, or assumes any legal liability or responsibility for the accuracy, completeness, or usefulness of any information, apparatus, product, or process disclosed, or represents that its use would not infringe privately owned rights. Reference herein to any specific commercial product, process, or service by trade name, trademark, manufacturer, or otherwise does not necessarily constitute or imply its endorsement, recommendation, or favoring by the United States Government or any agency thereof. The views and opinions of authors expressed herein do not necessarily state or reflect those of the United States Government or any agency thereof. 


\section{DISCLAIMER}

Portions of this document may be illegible in electronic image products. Images are produced from the best available original document. 


\begin{abstract}
The T2VOC computer model for simulating the transport of organic chemical contaminants in non-isothermal multiphase systems has been coupled to the ITOUGH2 code which solves parameter optimization problems. This allows one to use nonlinear programming and simulated annealing techniques to solve groundwater management problems, i.e. the optimization of multiphase aquifer remediation.
\end{abstract}

This report contains three illustrative examples to demonstrate the optimization of remediation operations by means of simulation-minimization techniques. The code iteratively determines an optimal remediation strategy (e.g. pumping schedule) which minimizes, for instance, pumping and energy costs, the time for cleanup, and residual contamination. While minimizing the objective function is straightforward, the relative weighting of different performance measures - e.g. pumping costs versus cleanup time versus residual contaminant content - is subject to a management decision process.

The intended audience of this report is someone who is familiar with numerical modeling of multiphase flow of contaminants, and who might actually use T2VOC in conjunction with ITOUGH2 to optimize the design of aquifer remediation operations. 


\section{TABLE OF CONTENTS}

Abstract $\ldots \ldots \ldots \ldots \ldots \ldots \ldots \ldots \ldots \ldots \ldots \ldots \ldots \ldots \ldots \ldots \ldots \ldots$

Table of Contents $\ldots \ldots \ldots \ldots \ldots \ldots \ldots \ldots \ldots \ldots \ldots \ldots \ldots$

List of Figures $\ldots \ldots \ldots \ldots \ldots \ldots \ldots \ldots \ldots \ldots \ldots \ldots$

List of Tables $\ldots \ldots \ldots \ldots \ldots \ldots \ldots \ldots \ldots \ldots \ldots \ldots \ldots$

1. Introduction $\ldots \ldots \ldots \ldots \ldots \ldots \ldots \ldots \ldots \ldots \ldots \ldots \ldots$

2. Problem No. 1: Optimizing pumping schedule $\ldots \ldots \ldots \ldots \ldots \ldots$

3. Problem No. 2: Optimizing steam displacement $\ldots \ldots \ldots \ldots \ldots \ldots \ldots$

4. Problem No. 3: Discontinuous cost function $\ldots \ldots \ldots \ldots \ldots \ldots$

5. Concluding remarks $\ldots \ldots \ldots \ldots \ldots \ldots \ldots \ldots \ldots \ldots \ldots \ldots \ldots$

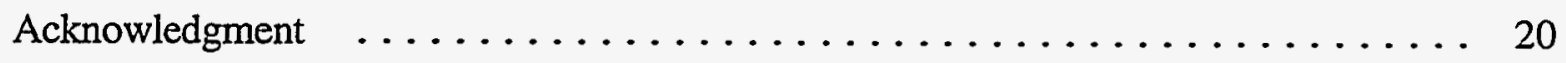

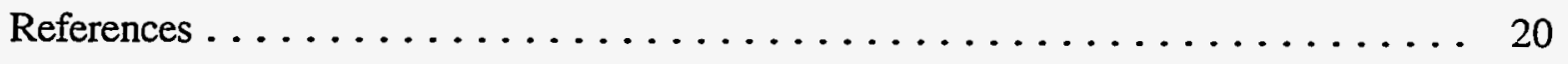

Appendix

A. Input files for sample problem No. $1 \ldots \ldots \ldots \ldots \ldots \ldots \ldots \ldots \ldots \ldots$

A1. T2VOC input file for sample problem no. 1 (excerpt) $\ldots \ldots \ldots \ldots \ldots 21$

A2. ITOUGH2 input file for sample problem no. $1 \ldots \ldots \ldots \ldots \ldots \ldots 22$

A3. Subroutine USEROBS for sample problem no. $1 \ldots \ldots \ldots \ldots \ldots$

B. ITOUGH2 input file for sample problem no. $2 \ldots \ldots \ldots \ldots \ldots \ldots$

C. Input files for sample problem No. $3 \ldots \ldots \ldots \ldots \ldots \ldots \ldots \ldots \ldots$

C1. ITOUGH2 input file for sample problem no. $3 \ldots \ldots \ldots \ldots \ldots \ldots$

C2. Subroutine USERPAR for sample problem no. $3 \ldots \ldots . \ldots . \ldots 29$ 


\section{LIST OF FIgURES}

Figure 1: Problem No. 1: Log permeability field of hypothetical contaminant site . . 4

Figure 2: Problem No. 1: NAPL saturation prior to remediation . . . . . . . . . 5

Figure 3: Problem No. 1: NAPL saturation after $30 \%$ of the contaminant mass has been removed, no optimization . ............... 5

Figure 4: Problem No. 1: NAPL saturation after $60 \%$ of the contaminant mass has been removed, no optimization . . . . . . . . . . . . . 6

Figure 5: Problem No. 1: NAPL saturation after $90 \%$ of the contaminant mass has been removed, no optimization ................... 6

Figure 6: Problem No. 1: NAPL saturation after $30 \%$ of the contaminant mass has been removed $\ldots \ldots \ldots \ldots \ldots \ldots \ldots \ldots \ldots \ldots \ldots \ldots \ldots \ldots$

Figure 7: Problem No. 1: NAPL saturation after $30 \%$ of the contaminant mass has

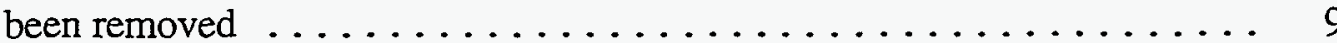

Figure 8: Problem No. 1: NAPL saturation after $30 \%$ of the contaminant mass has

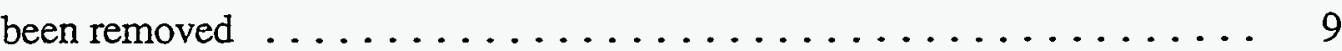

Figure 9: Problem No. 2: Initial liquid saturation . . . . . . . . . . . . 13

Figure 10: Problem No. 2: Xylene saturation after injection $\ldots \ldots \ldots \ldots$

Figure 11: Problem No. 2: Xylene saturation prior to steam injection . . . . . . . 13

Figure 12: Problem No. 2: Xylene saturation after 100 days of steam injection $\ldots . .13$

Figure 13: Problem No. 2: Total costs as a function of injection rate and steam enthalpy 15

Figure 14: Problem No. 3: NAPL saturation after $60 \%$ of the contaminant mass has been removed, no optimization . . . . . . . . . . . . . 19

Figure 15: Problem No. 3: NAPL saturation after $60 \%$ of the contaminant mass has been removed, optimized . . . . . . . . . . . . . . . . . . . 19

\section{LIST OF TABLES}

Table 1: $\quad$ Parameter set $\ldots \ldots \ldots \ldots \ldots \ldots \ldots \ldots \ldots \ldots$

Table 2: Sample No. 1: Optimum pumping schedule $\ldots \ldots \ldots \ldots \ldots$

Table 3: Sample No. 2: Optimization results $\ldots \ldots \ldots \ldots \ldots$ 


\section{Introduction}

The design of a cleanup operation for a contaminated aquifer comprises problems of a hydrological, technical, environmental, and economic nature. The main task is to select an effective and efficient remediation technology. The suitability of a proposed method depends on the chemical properties of the contaminant, the characteristics of the aquifer, and the overall remediation goals. Once a technology (e.g. steam injection) has been chosen, the operational scheme (e.g. pumping volumes and steam temperature) can be further optimized to reduce remediation costs.

Standard groundwater remediation operations include some form of pumping through extraction wells and subsequent treatment of the contaminated groundwater. Hazardous volatile nonaqueous phase liquids may be efficiently removed from contaminated soils and aquifers by injecting steam, thus vaporizing and displacing the contaminant toward the extraction wells. The use of numerical models to study different remediation designs requires simulating the transport of organic chemical contaminants in non-isothermal multiphase flow systems. In this study, we use the T2VOC code [Falta et al., 1994], which is an adaptation of the STMVOC numerical simulator developed at Lawrence Berkeley Laboratory by R. Falta and K. Pruess [Falta and Pruess, 1991], for modeling contaminant transport.

The management of groundwater remediation by means of optimization techniques usually aims at maximizing contaminant removal by a minimum of capital, operating, and maintenance costs. Furthermore, technical constraints and regulatory cleanup standards have to be observed. It is important to realize that the optimization techniques discussed in this report only address the issue of finding parameters for which a cost function reaches a minimum. Prior to the minimization of the cost function, a number of conceptual decisions has to be made, including, first of all, the choice of an appropriate remediation technology, the definition of the performance measure, and the selection of the parameters to be considered as variables for optimization. Furthermore, the relative weighting between different remediation goals (for example, minimal remediation costs versus short cleanup time versus acceptable residual contaminant concentration in the aquifer) is an important, albeit highly controversial issue which has to be resolved by the remediation manager before the design can be optimized by the methods discussed here.

The purpose of this report is to demonstrate how standard parameter estimation methods can be used to optimize remediation strategies. The ITOUGH2 code [Finsterle, 1993] was 
originally developed for the estimation of hydrogeologic model parameters for the TOUGH2 code [Pruess, 1987, 1991] and some of its descendants, such as T2VOC. ITOUGH2 solves the inverse problem by automatic model calibration using standard non-linear optimization techniques. In principle, the same methodology can be applied to optimize remediation strategies by minimizing an appropriately defined objective (or cost) function.

Three illustrative examples are presented in this study. The first example examines the remediation of a large contaminant plume by an array of extraction wells. The pumping rate in each well is optimized to reduce cleanup costs. The second example is taken from the STMVOC user's guide [Problem No. 4, Falta and Pruess, 1991] and considers steam displacement of a hazardous non-aqueous phase liquid (NAPL) in a two-dimensional crosssectional system. The injection and extraction scheme is optimized to reduce cleanup time as well as pumping and energy costs. The configuration of the third example is similar to the first one. However, a more complicated, discontinuous cost function is introduced and optimized using a simulated annealing algorithm.

This study shows that the techniques developed for estimating model parameters can be successfully applied to solve remediation management problems. However, the resulting optimum pumping scheme strongly depends on the formulation of the remediation goals, and the relative weighting between individual terms of the cost function. Given this fact it is suggested that only well defined objective functions shall be used to determine a limited set of design parameters. The solution may then point towards alternative remediation schemes with the potential of increasing effectiveness and decreasing costs.

This report is most useful for someone who is familiar with numerical modeling of multiphase flow of contaminants, and who might actually want to use T2VOC in conjunction with ITOUGH2 to optimize the design of aquifer remediation operations. We thus have included a number of input files and subroutine listings in the Appendices.

\section{Problem No. 1: Optimizing Pumping Schedule}

Consider a confined aquifer of uniform thickness $(10 \mathrm{~m})$, contaminated by a spill of xylene. Xylene has a molecular weight of $106.168 \mathrm{~g} / \mathrm{mol}$, a density of $880 \mathrm{~kg} / \mathrm{m}^{3}$ at $20{ }^{\circ} \mathrm{C}$, and a solubility in water of $2.975 \mathrm{E}-5$ [mole fraction]. It is assumed that 3 years after release, the pollution is discovered, stopped, and the spatial distribution of the contaminant is 
determined. Subsequently, an array of wells is installed to remediate the aquifer. The aquifer is heterogeneous in hydraulic conductivity with a mean permeability of $10^{-11} \mathrm{~m}^{2}$, a standard deviation of one order of magnitude, a correlation length of $100 \mathrm{~m}$ along the main west-east flow direction, and a correlation length of $20 \mathrm{~m}$ in the perpendicular direction. Effective porosity is 0.3 . A natural hydraulic gradient of 0.01 is imposed across the model domain of $200 \mathrm{~m}$ length. There is no flow across the northern and southern boundaries.

We realize that the unsaturated zone as well as density effects (concentration of xylene near the top of the aquifer) are important aspects of plume migration which are not accounted for due to the two-dimensional nature of the model. Nevertheless, we believe that a simplified process description and aquifer representation is acceptable since the main purpose of this study is to demonstrate the applicability of inverse modeling techniques to the optimization of remediation operations.

The parameter set for the sample problem is summarized in Table 1. The permeability field, the location of the contaminant source (square), and the pumping wells (circles) are shown in Figure 1. The plume after 3 years of continuous release of contaminant is depicted in Figure 2.

Subsequently, pumping of groundwater at a constant rate of $2.0 \mathrm{~kg} / \mathrm{s}$ in each well is started. The location of the plume, i.e. the NAPL saturation, is shown in Figures 3, 4, and 5 after 30,60 , and $90 \%$ of the original amount of contaminant is removed, respectively. Note that a relatively small percentage of the total contaminant inventory is dissolved in the water phase, flowing downstream at a higher velocity than the NAPL plume. Initially, most of the xylene is present as a free and mobile NAPL phase. The time required to remove the first $30 \%$ of the total initial contaminant mass is calculated to be 40 days, whereas it takes more than 8 years to remove an additional $60 \%$. This is mainly due to the strongly reduced effective permeability. at low NAPL saturations, and because a stagnation zone is formed between the wells. This means that the contaminant is removed basically by pumping groundwater, in which the chemical is dissolved. Obviously, this remediation scheme is inefficient and can be improved by optimizing the pumping schedule for individual wells and individual stages during the cleanup operation as will be discussed in the remainder of this section. 


\begin{tabular}{|l|c|c|}
\hline Parameter & Unit & Value \\
\hline mean permeability $\mathrm{k}$ & $\mathrm{m}^{2}$ & $10^{-11}$ \\
variance of $\log (\mathrm{k})$ & $\mathrm{m}$ & 1.0 \\
correlation length in X-direction & $\mathrm{m}$ & 100.0 \\
correlation length in y-direction & - & 20.0 \\
\hline porosity & & 0.3 \\
\hline relative permeability function: Stone [1970] & - & \\
$\mathrm{S}_{\mathrm{wr}}$ & - & 0.10 \\
$\mathrm{~S}_{\mathrm{nr}}$ & - & 0.05 \\
$\mathrm{~S}_{\mathrm{gr}}$ & - & 0.01 \\
$\mathrm{n}$ & & 3.00 \\
\hline capillary pressure function: Parker et al. $[1987]$ & - & 0.00 \\
$\mathrm{~S}_{\mathrm{m}}$ & - & 1.84 \\
$\mathrm{n}$ & $\mathrm{m}^{-1}$ & 50000.00 \\
$\alpha_{\mathrm{gn}}$ & $\mathrm{m}^{-1}$ & 5.24 \\
$\alpha_{\mathrm{nw}}$ & & \\
\hline boundary conditions & bar & 1.20 \\
pressure at west boundary & bar & 1.00 \\
\hline pressure at east boundary & & \\
\hline
\end{tabular}

Table 1: Parameter set

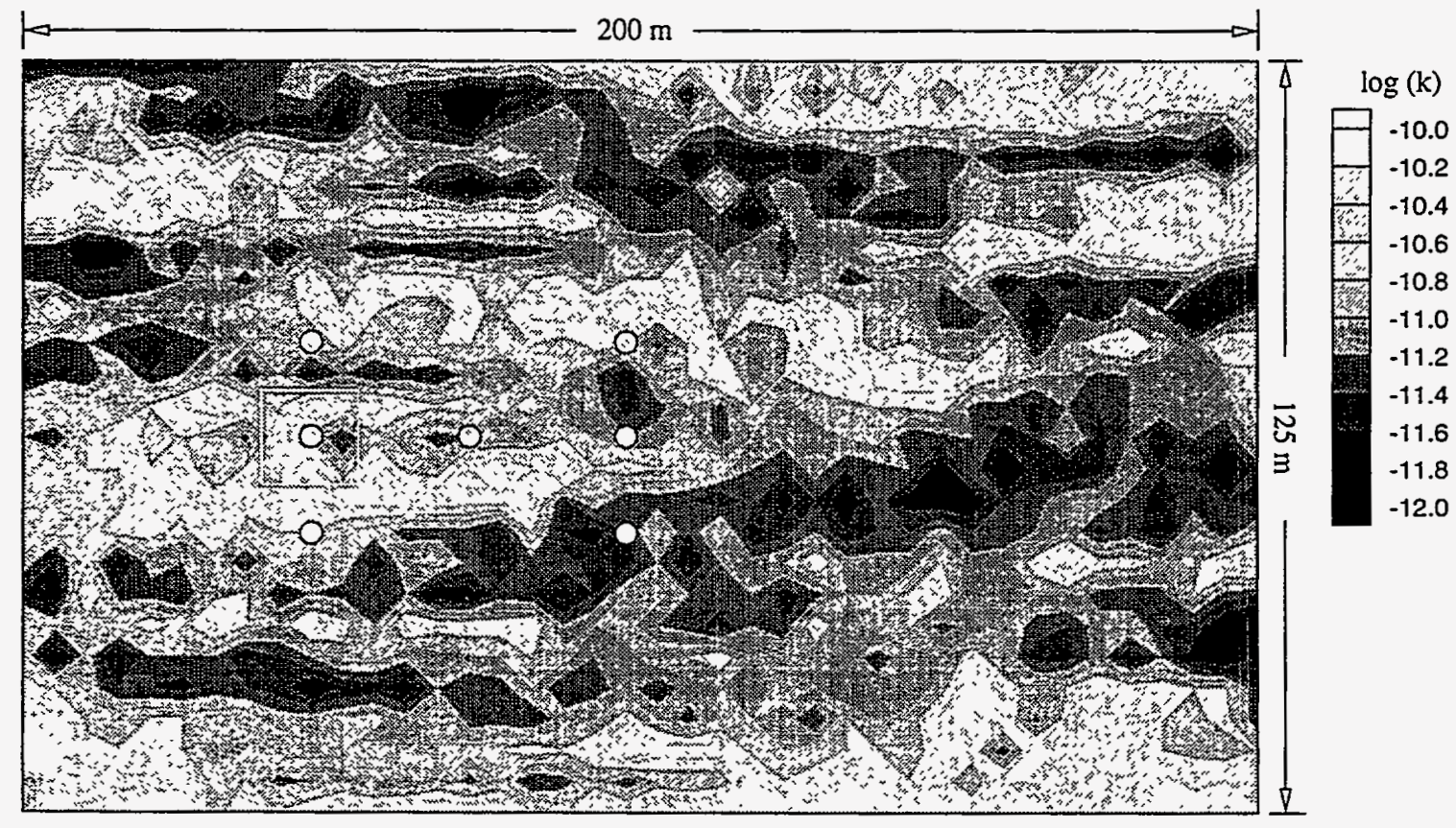

Figure 1: Problem No. 1: Log permeability field of hypothetical contaminant site 


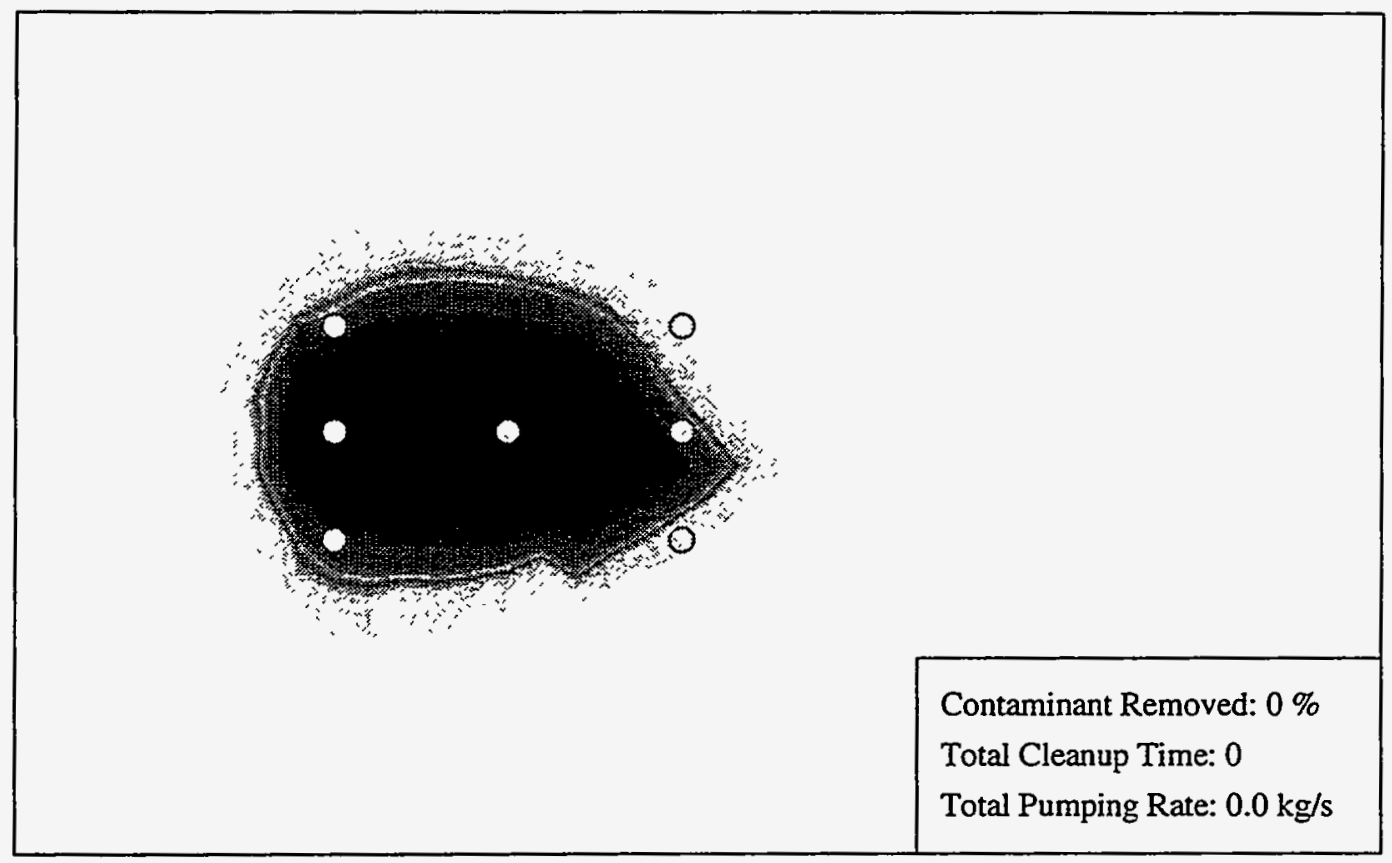

Figure 2: Problem No. 1: NAPL saturation prior to remediation

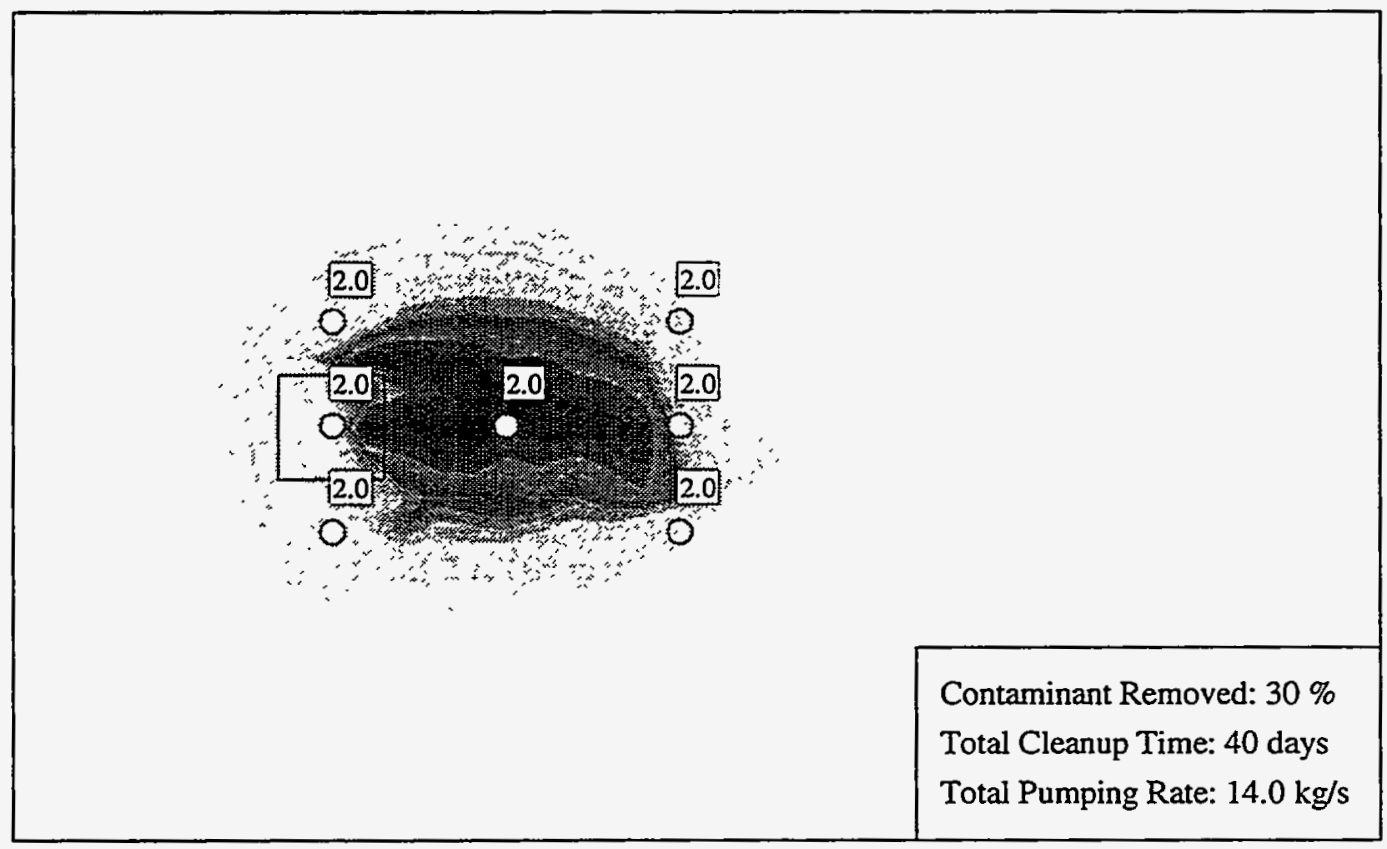

Figure 3: Problem No. 1: NAPL saturation after $30 \%$ of the contaminant mass has been removed, no optimization. Individual pumping rates are shown in boxes at wells. 


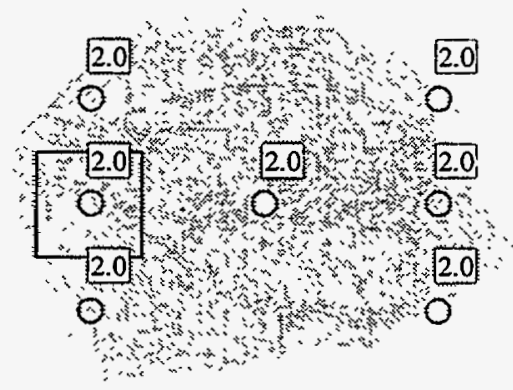

Contaminant Removed: $60 \%$

Total Cleanup Time: 260 days

Total Pumping Rate: $14.0 \mathrm{~kg} / \mathrm{s}$

Figure 4: Problem No. 1: NAPL saturation after $60 \%$ of the contaminant mass has been removed, no optimization. Individual pumping rates are shown in boxes at wells.

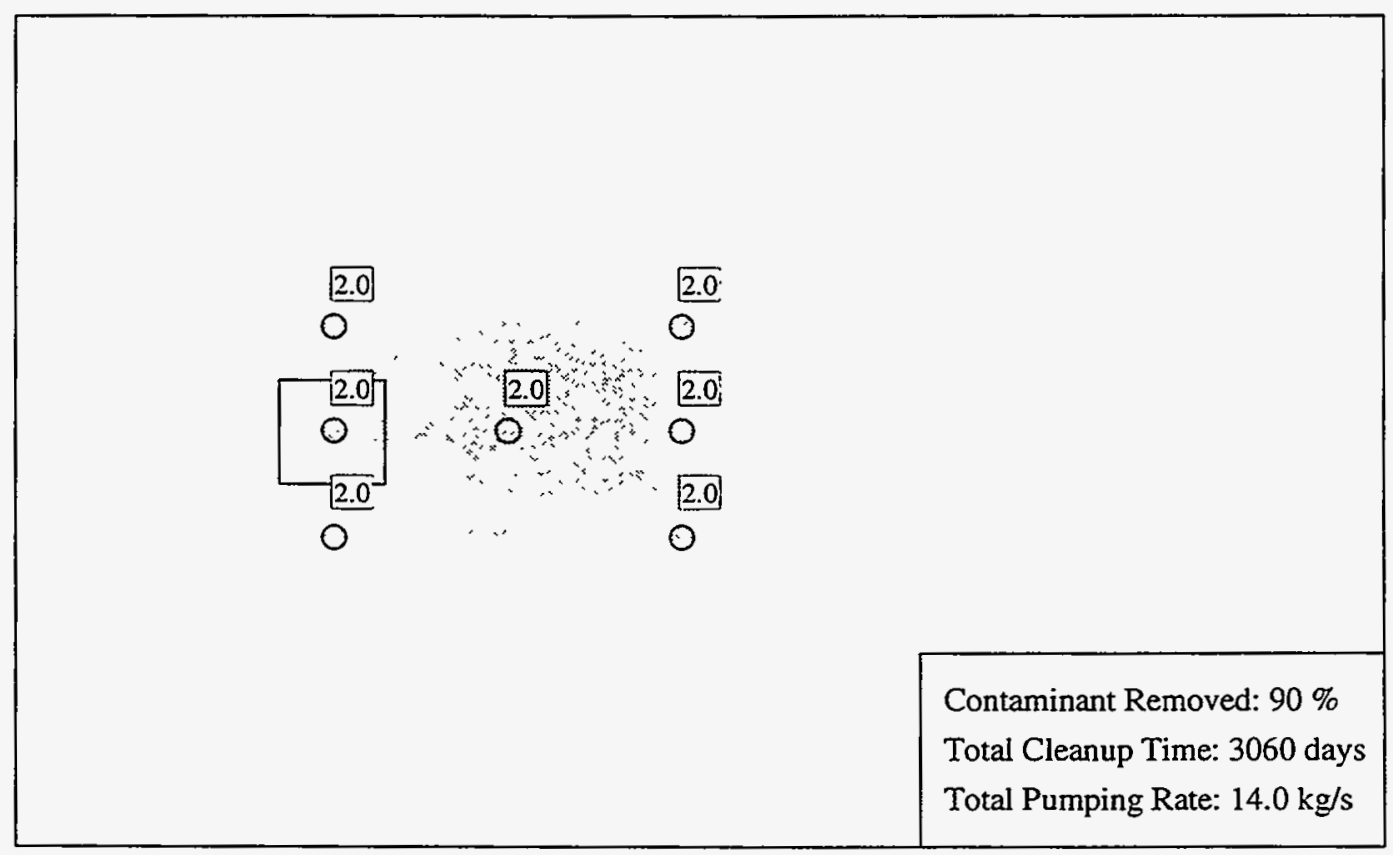

Figure 5: Problem No. 1: NAPL saturation after $90 \%$ of the contaminant mass has been removed, no optimization. Individual pumping rates are shown in boxes at wells. 
We determined three optimum pumping schedules for three phases of the cleanup operation. Since the location of the plume as well as its spreading changes with time, it is expected that the pumping rates have to be changed with time to achieve a maximum remediation of the aquifer. In this study we change the pumping schedule after 30 and $60 \%$ of the contaminant has been removed. The objective function to be minimized is simply the total amount of fluid that needs to be pumped, i.e. the product of pumping rate times cleanup time, totaled for all wells. Each pump is assumed to have a maximum capacity of 4 l/s.

The T2VOC code has been slightly modified to allow the automatic cessation of the simulation if the total amount of hydrocarbon in the system is lower than a certain predefined value (e.g. $70 \%$ of the initial inventory). The actual cleanup time is then calculated by linear interpolation between the two last time steps. In ITOUGH2, the objective function to be minimized is provided through a user specified observation type which calculates the product of pumping rate and cleanup time for each well. In inverse modeling terminology, the difference between the total amount of fluid calculated by T2VOC and the "measured" value of zero is to be minimized using the $\mathrm{L}_{1}$-estimator. Since the product of total pumping rate times cleanup time is not a standard ITOUGH2 observation type, this has to be programmed into subroutine USEROBS, an interface subroutine provided by the code. The T2VOC and ITOUGH2 input files as well as subroutine USEROBS are reproduced in Appendix A.

The pumping schedule, cleanup time, and mean NAPL concentration of the extracted two-phase NAPL-groundwater mixture, as well as the total amount pumped are summarized in Table 2. The values for the original design prior to optimization are also shown for comparison. The NAPL distribution after 30,60 , and $90 \%$ of the initial contaminant mass has been removed is visualized in Figures 6 through 8 . 


\begin{tabular}{|l|c|c|c|c|}
\hline \multirow{2}{*}{ Contaminant removed } & \multicolumn{4}{|c|}{ Pumping rate [kg/s] } \\
\cline { 2 - 5 } & $30 \%$ & $60 \%$ & $90 \%$ & $90 \%$ \\
\hline Well NW & 1.9 & 0.1 & 0.0 & 2.0 \\
Well NE & 0.0 & 0.0 & 0.0 & 2.0 \\
Well CW & 4.0 & 0.9 & 0.6 & 2.0 \\
Well CC & 4.0 & 3.1 & 3.2 & 2.0 \\
Well CE & 4.0 & 3.9 & 3.0 & 2.0 \\
Well SW & 2.1 & 0.1 & 0.5 & 2.0 \\
Well SE & 0.2 & 0.6 & 0.0 & 2.0 \\
\hline Total pumping rate [kg/s] & 16.3 & 8.7 & 7.3 & 14.0 \\
\hline Total cleanup time [day] & 20 & 180 & 3110 & 3060 \\
\hline NAPL/water ratio at wells [gr/kg] & 16.7 & 6.3 & 0.6 & 0.4 \\
\hline Total mass pumped [106 kg] & 28 & 148 & 2270 & 3700 \\
\hline
\end{tabular}

Table 2: Sample No. 1: Optimum pumping schedule

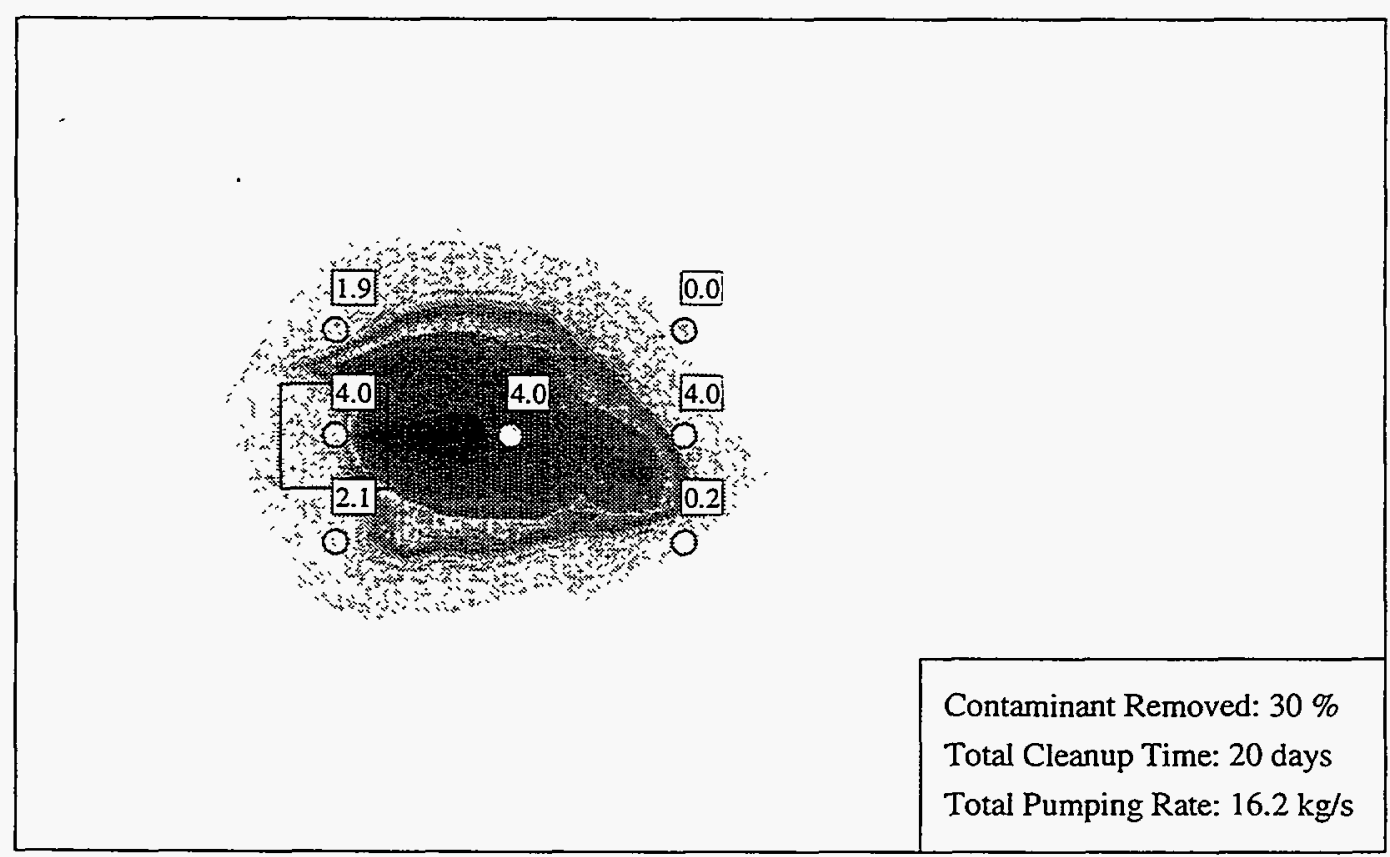

Figure 6: Problem No. 1: NAPL saturation after $30 \%$ of the contaminant has been removed. Individual pumping rates are shown in boxes at wells. 
Contaminant Removed: $60 \%$

Total Cleanup Time: 180 days

Total Pumping Rate: 8.7 kg/s

Figure 7: Problem No. 1: NAPL saturation after $60 \%$ of the contaminant has been removed. Individual pumping rates are shown in boxes at wells.

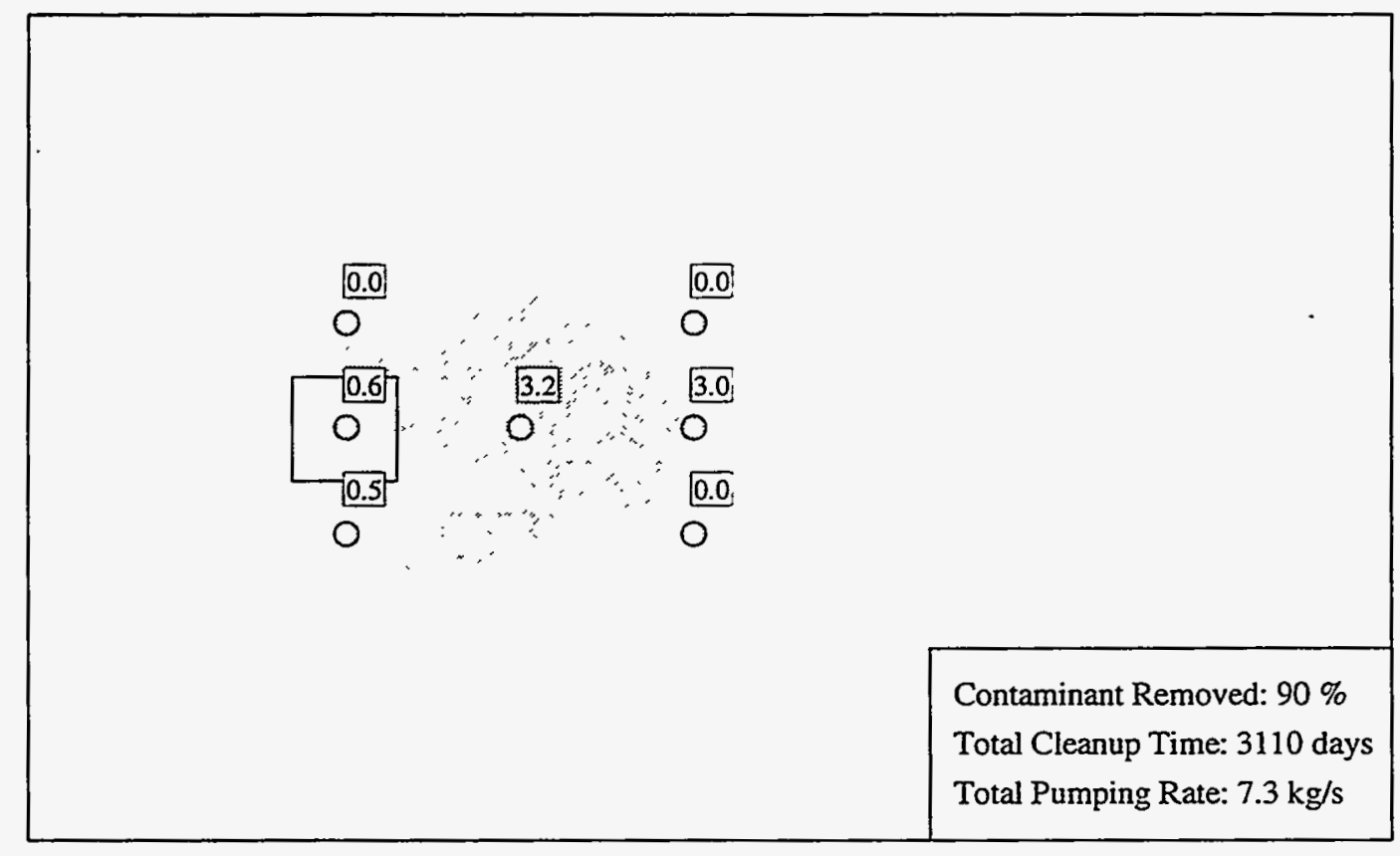

Figure 8: Problem No. 1: NAPL saturation after $90 \%$ of the contaminant has been removed. Individual pumping rates are shown in boxes at wells. 
For the initial period of the cleanup operation, the result of the optimization procedure suggests pumping the center wells at full capacity, and extracting contaminated groundwater also from the two wells on the west side of the field. The two wells to the east are almost shut down, because the water has low NAPL concentrations in that region.

During the second cleanup period, where the total contaminant content is reduced from 70 to $40 \%$ of the initial amount, the pumping rates in the western wells are lowered to avoid the formation of a stagnation zone. Part of the plume has moved east following the general groundwater flow, favoring extraction from wells center-east (CE) and south-east (SE) which are further downstream. Extracting an additional $30 \%$ of the initial contaminant content requires pumping for a long period at a relatively low rate. Notice that the total duration of the cleanup operation is not shorter than for the initial design, but the total amount of removed groundwater is reduced by more than $50 \%$, leading to a higher contaminant concentration in the extracted fluid. If the duration of the cleanup is an issue, optimization of remediation time can be included by appending an additional term to the objective function. This is briefly discussed in sample problem No. 2 below.

One might argue that the solution of the optimization is non-unique and strongly depends on the pumping rate initially assigned to each well. There is a hydrological reason for this unstable behavior. If a certain well starts out with a higher pumping rate than an adjacent well, the flow field and therefore the contaminant plume moves preferentially toward this well. This makes the neighboring well even less efficient because water of lower contaminant concentration is removed. Depending on the flow distances and the size and shape of the plume, it is often preferable to shut down peripheral wells, thus concentrating the remediation effort to a few wells in the center of the plume. The instability may also be invoked by local heterogeneities of the aquifer.

Despite the problem of non-uniqueness, each proposed solution of similar efficiency is a valuable alternative which can aid in the design of an improved remediation. Given the optimum pumping schedule presented above, one might want to revise the number and location of the wells, thus reducing installation costs. The new well configuration can then be optimized in the same manner. Moreover, the long pumping period required to remove the contaminant suggests that another remediation technique may be more appropriate. For example, one might consider using air or steam injection to enhance the recovery of contaminant since the low mobility of the contaminant near residual saturation is the main reason for the inefficiency of the pump and treat method. 


\section{Problem No. 2: Optimizing NAPL Removal by Steam Injection}

The second example is taken from the STMVOC user's guide [Falta and Pruess, 1991]. A two-dimensional, vertical (cross section) field scale system is considered with an initially undisturbed water table and a static pressure distribution as shown in Figure 9. The homogeneous soil exhibits a permeability of $2.5 \cdot 10^{-13} \mathrm{~m}^{2}$. All other parameters are identical to the ones listed in Table 1. A total of $704 \mathrm{~kg}$ of xylene is injected into the top center of the model domain (see Figure 10) and allowed to drain down towards the water table (Figure 11). The NAPL distribution shown in Figure 11 (which is a different representation of the data in Figure 23 in Falta and Pruess [1991]) depicts the initial condition for the subsequent remediation effort. Steam is injected from a well at the left boundary, and a deliverability condition is applied at the right boundary, representing an extraction well. The distance between the two wells is $18.3 \mathrm{~m}$. As shown in Falta and Pruess [1991], the steam is effectively sweeping the xylene toward the extraction well (Figure 12), and after 153 days, the total xylene content in the system is reduced to $5 \%$ of the original amount.

In this example, we assume that the duration of the cleanup operation is limited to 140 days. At the same time, we would like to minimize pumping costs, energy costs, and residual xylene content by varying the amount and temperature of the injected steam. In order to demonstrate the use of a more complex objective function, we assume that the pumping costs are not only a function of the rate but also of the pressure difference and fluid density. Provided that an electrical pump is operating with a certain efficiency $(f<1)$, the energy costs for the pumps amount to:

$$
C_{\text {pump }}=\frac{|\mathrm{q} \cdot \Delta \mathrm{p}|}{\rho} \cdot \Delta \mathrm{t} \cdot \frac{\mathrm{c}_{\text {energy }}}{\mathrm{f}}
$$

where

$$
\begin{array}{lll}
\mathrm{C}_{\text {pump }} & : & \text { costs of electrical pump [\$] } \\
\mathrm{q} & : & \text { pumping rate }[\mathrm{kg} / \mathrm{s}] \\
\Delta \mathrm{p} & : & \text { pressure change at pump }[\mathrm{Pa}] \\
\rho & : & \text { fluid density }\left[\mathrm{kg} / \mathrm{m}^{3}\right] \\
\Delta \mathrm{t} & : & \text { period of operation }[\mathrm{s}] \\
\mathrm{f} & : & \text { efficiency of electrical pump }[-] \\
\mathrm{c}_{\text {energy }} & : & \text { specific energy costs }[\$ / \mathrm{J}]
\end{array}
$$


Furthermore, we would like to add costs for the treatment of the contaminated groundwater. In practice, treatment costs may be a complicated function of the chemical composition, concentration, and amount of the wastewater being pumped. One might also consider to only treat water the concentration of which exceeds a certain minimum level. In this study, we assume that the costs for treating a certain amount of wastewater are constant:

$$
\mathrm{C}_{\text {treat }}=\mathrm{q} \cdot \Delta \mathrm{t} \cdot \mathrm{c}_{\text {treat }}
$$

where

$C_{\text {treat }}:$ costs to treat wastewater [\$]

$c_{\text {treat }}:$ specific treatment costs $[\$ / \mathrm{kg}]$

The energy costs for producing steam of a certain enthalpy can be described as

$$
\mathrm{C}_{\text {steam }}=\mathrm{q} \cdot \Delta \mathrm{t} \cdot \Delta \mathrm{h} \cdot \mathrm{C}_{\text {energy }}
$$

where

$\mathrm{C}_{\text {steam }}$ : additional energy costs to produce steam of higher enthalpy [\$]

h : specific enthalpy of steam $[\mathrm{J} / \mathrm{kg}]$

Finally, the residual amount of xylene in the aquifer should be as low as possible. In order to achieve this goal, we impose hypothetical costs to each kilogram of xylene that has not been removed from the system.

$$
\mathrm{C}_{\text {clean }}=\mathrm{m}_{\mathrm{xylene}} \cdot \mathrm{c}_{\mathrm{xylene}}
$$

where

$\mathrm{C}_{\text {clean }}$ : hypothetical costs for incomplete remediation [\$]

$\mathrm{m}_{\mathrm{xylene}}:$ xylene mass not removed from the aquifer $[\mathrm{kg}]$

$c_{x y l e n e}:$ specific costs for inremediated contaminant $[\$ / \mathrm{kg}]$

The total costs to be minimized are therefore:

$$
\text { Minimize } \quad C_{\text {tot }}=C_{\text {pump }}+C_{\text {treat }}+C_{\text {steam }}+C_{\text {clean }}
$$

It should be realized that these costs do not represent the total costs of the remediation operation. They only represent the variable costs that depend on a change of the pumping scheme and the temperature of the injected steam. It is thus not necessary to calculate the absolute dollar figures. However, the relative costs for each term in (5) are of importance. 


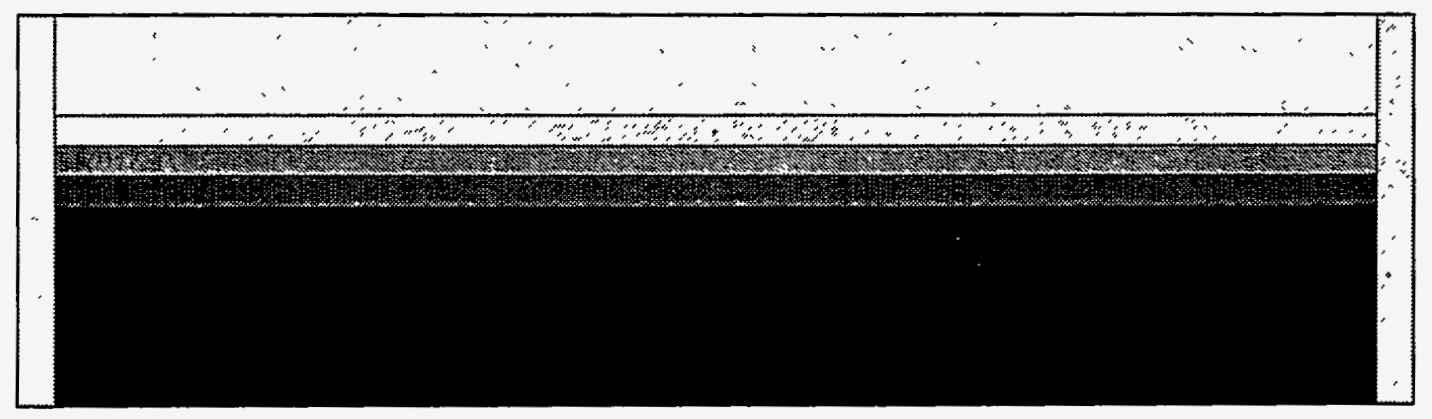

Figure 9: Problem No. 2: Initial liquid saturation

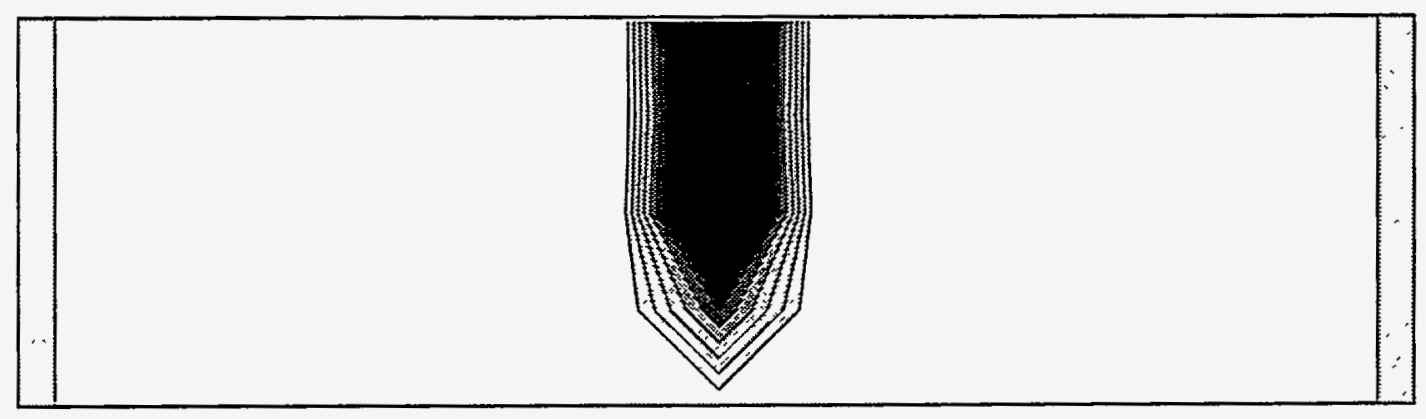

Xylene Saturation

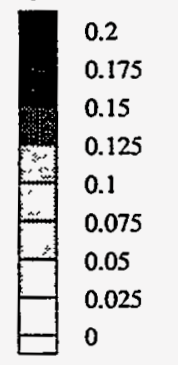

Figure 10: Problem No. 2: Xylene saturation after injection

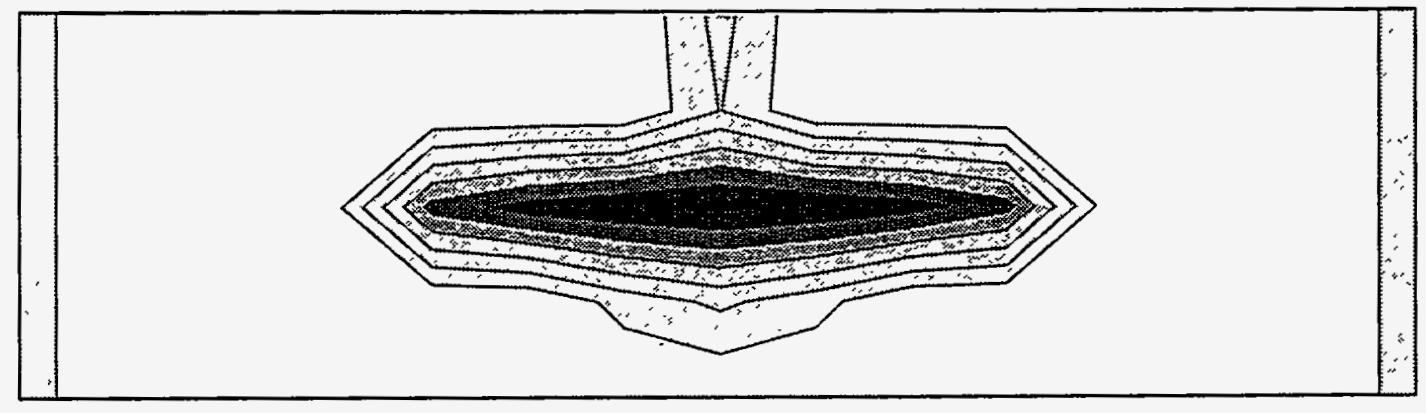

Xylene Saturation

0.15

0.125

0.1

0.075

0.05

0.025

Figure 11: Problem No. 2: Xylene saturation prior to steam injection

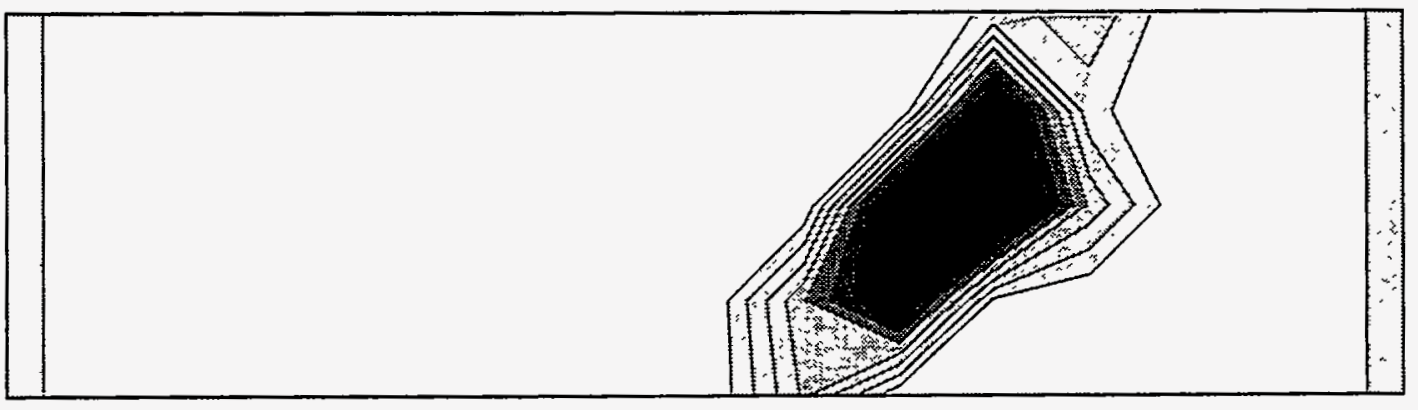

Figure 12: Problem No. 2: Xylene saturation after 100 days of steam injection 
More sophisticated models can be applied to calculate the costs for treating the wastewater. For example, the concentration of the contaminant in the extracted groundwater may influence the efficiency of the subsequent chemical processing. One has to keep in mind, however, that not only the absolute costs, but also the relative weighting between individual costs determines the solution to the optimization problem. Weighting remediation goals of different nature is a decision process that involves a great deal of subjective judgment and is not amenable to mathematical description.

The following values are used for the hypothetical case: $f=0.2, c_{\text {energy }}=3.33 \cdot 10^{-8} \$ / \mathrm{J}$ $(=0.12 \$ / \mathrm{kWh}), c_{\text {treat }}=0.01 \$ / \mathrm{kg}$, and $c_{x y l e n e}=2.0 \$ / \mathrm{kg}$. The ITOUGH2 code was run to determine the optimum parameter combination (steam enthalpy and injection rate). The ITOUGH2 input file for this run is reproduced in Appendix B. The total costs could be reduced by $40 \%$. However, the eigenanalysis of the covariance matrix indicated that the solution is very uncertain and probably highly non-unique. This presumption was confirmed by running the optimization for different initial guesses which yielded different optimum solutions on approximately the same cost level.

The situation is visualized in Figure 13, where the total costs (Eq. 5) are contoured as a function of steam enthalpy and injection rate. Figure 13 was created by running the T2VOC code 400 times for as many parameter combinations. The objective function exhibits a region of high total costs (dark) and one of low total costs (light). The transition between the two plateaus is very steep. This is because the contaminant is quickly removed once the front of the plume has reached the extraction well. As a consequence of this particular system behavior, most pumping schedules with low injection rates are not acceptable because they do not meet the primary remediation goal of actually removing the contaminant. In the transition zone, the additional energy and pumping costs associated with an increase of the injection rate or enthalpy are small compared to the benefit that results from a higher amount of xylene that is removed from the aquifer. Finally, once the plume can be extracted within 140 days, there is no need for higher injection rates or steam temperatures. However, the objective function in the right part of Figure 13 increases slightly due to the higher costs associated with the inefficient pumping of almost clean fluid. Note that an increase of the injection rate affects both the pumping costs and the energy costs to generate more steam, whereas increasing the temperature only raises energy costs. On the other hand, increasing the injection rate is much more efficient in reducing the final xylene content which explains its overall high sensitivity. It is important to realize that this particular shape of the objective 
function reflects the high weight that was given to the total amount of removed contaminant at the end of the cleanup operation.

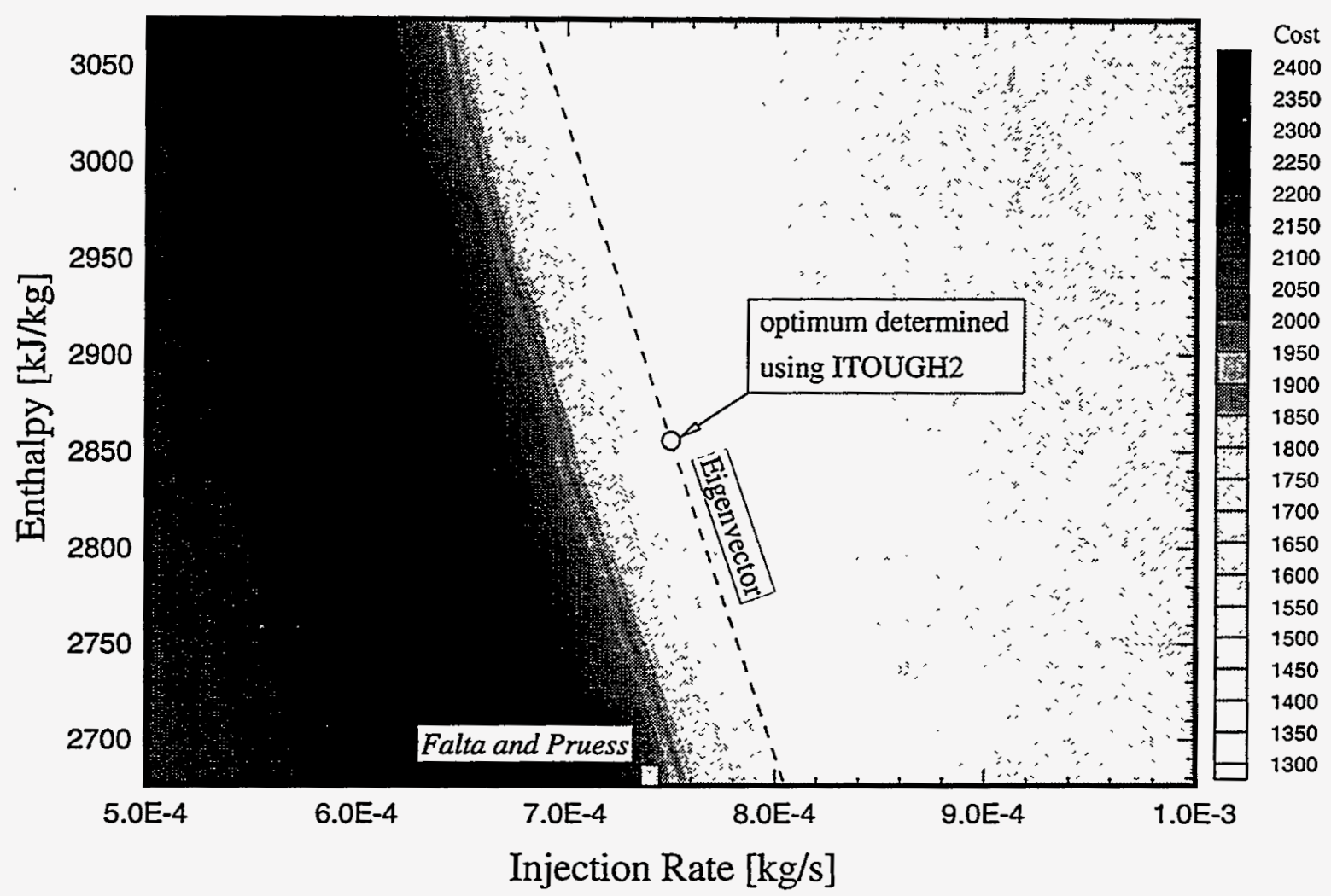

Figure 13: Problem No. 2: Total costs as a function of injection rate and steam enthalpy

The results of the optimization are summarized in Table 3. The values for the original remediation specifications used by Falta and Pruess [1991] are also given for comparison and shown as a square in Figure 13. Obviously, the solution of the optimization problem is nonunique. All parameter combinations along the base of the valley are valid alternatives. This conclusion can also be obtained by interpreting the eigenvalues and eigenvectors of the covariance matrix. The orientation of the valley was accurately predicted by the components of the longest eigenvector. The eigenvalue itself indicated that the solution is non-unique within the range of acceptable steam enthalpies. A confidence region can then be drawn which contains alternative solutions of the optimization problem. Obviously, the linearity assumption of this first-order error analysis is violated since the change of costs is very different if moving in opposite directions along the shortest eigenvector. However, this fact 
is easily detected by evaluating the objective function at the endpoints of the eigenvectors (for details see [Finsterle and Pruess, 1993]). The result of this procedure suggests that a more conservative answer to the optimization problem is obtained by shifting the solution along the shortest eigenvector toward higher injection rates and higher steam temperatures. Solution of the optimization problem required only 23 iterations, i.e. 23 forward runs of the flow and transport model T2VOC.

Alternative pumping schemes with equally low costs are near the line given by Equation 6, which is derived from the components of the largest eigenvector and one of the ITOUGH2 solutions, indicated by a circle in Figure 13:

$$
\mathrm{q}=8.04 \mathrm{E}-4-3.0 \mathrm{E}-10 \cdot(\mathrm{h}-2.676 \mathrm{E} 6)
$$

\begin{tabular}{|l|c|c|c|}
\hline & Units & $\begin{array}{c}\text { Falta and Pruess } \\
{[1991]}\end{array}$ & Optimized \\
\hline Design variables & $\mathrm{kJ} / \mathrm{kg}$ & 2676 & (2854) Eq. (6) \\
\hline Steam enthalpy & $\mathrm{kg} / \mathrm{s}$ & $7.4 \mathrm{E}-4$ & $(7.6 \mathrm{E}-4) \mathrm{Eq} .(6)$ \\
\hline Injection rate & $\$$ & 776 & (851) variable \\
\hline Costs & $\$$ & 129 & (145) variable \\
\hline Steam generation: $\mathrm{C}_{\text {steam }}$ & $\$$ & 289 & (291) variable \\
\hline Pumping costs: $\mathrm{C}_{\text {pump }}$ & $\$$ & 880 & (3) variable \\
\hline Wastewater treatment: $\mathrm{C}_{\text {treat }}$ & $\$$ & 2074 & 1290 \\
\hline Cost for incomplete remediation: $\mathrm{C}_{\mathrm{xyllene}}$ & $\$$ & & \\
\hline Total costs & &
\end{tabular}

Table 3: Sample No. 2: Optimization results 


\section{Problem No. 3: Discontinuous Cost Function}

The nonlinear programming technique applied in the previous examples requires the computation of sensitivity coefficients of cleanup costs with respect to the decision variables, i.e. the pumping rates. In many cases, however, the cost functions are discontinuous (see discussion below). Furthermore, the objective function tends to be highly nonlinear and nonconvex, so there is no guarantee that a global optimum will be found by applying gradientbased minimization algorithms. Combinatorial optimization methods such as genetic algorithms or simulated annealing use a random search scheme inspired by biological evolution or the annealing process of metals, respectively.

In this last example we employ simulated annealing (SA) minimization to search for optimal remediation designs. We consider the same aquifer and initial conditions as in problem No. 1. However, the number of wells and well configuration is slightly changed (see Figure 14). Furthermore, we require that the extracted water be treated and reinjected to the aquifer. A simplified design was chosen, where pairs of wells are connected in north-south direction. One well extracts contaminated groundwater, and the other well is used for reinjection after phase separation and stripping of the volatile organic compound is performed. We neglect the loss of mass during the remediation process and assume that the same amount of water is reinjected as the mass of fluid previously withdrawn. The extraction/injection rates for the four pairs of wells are the design parameters to be optimized. The user has to include this special parameter into subroutine USERPAR which is reproduced in Appendix C2.

The objective function to be minimized consists of capital and operational costs written as:

$$
C=\alpha\left[c_{w e l l}+|q| \cdot t \cdot\left(\frac{|\Delta p| \cdot c_{\text {energy }}}{\rho \cdot f}+\frac{c_{\text {treat }}}{2}\right)+\beta\right]
$$

where $\alpha$ is a penalty factor and $\beta$ is a penalty cost. We assume that no well is drilled if the pumping rate is below a certain value $q_{\min }$. This can be handled by multiplying the costs by $\alpha$, which is zero for $|q|<q_{\min }$, and 1 for $|q| \geq q_{\min }$. We also introduce fixed costs for drilling and equipping a well, $c_{\text {well }}$. Furthermore, we require that the maximum time allowed to remove $60 \%$ of the xylene plume is restricted. Again, a penalty $\operatorname{cost} \beta$ is used, which assumes a large value if the cleanup time exceeds $t_{\max }$. In this study, the minimum pumping rate is set to $q_{\min }=0.2 \mathrm{~kg} / \mathrm{s}$, the maximum cleanup time is $t_{\max }=5$ years, and the capital cost for a well is $c_{\text {well }}=\$ 10,000$. 
Note that the cost function (9) and its derivative is discontinuous at $|q|=q_{\min }$ and $t=t_{\max }$. This makes it difficult for gradient-based minimization algorithm to converge to a minimum which is, moreover, likely to be only a local one. The method of simulated annealing is designed to handle discontinuous objective functions and is able to overcome local minima by accepting uphill steps with a certain probability. The ITOUGH2 input file for sample problem No. 3 is included in Appendix Cl.

For comparison and as initial conditions for the optimization, we simulate aquifer cleanup by pumping from the four southern wells at a rate of $-2.0 \mathrm{~kg} / \mathrm{s}$, and injecting the cleaned water in the four wells to the north. The xylene saturation for this case is shown in Figure 14. Note that contaminant is displaced from the center injection well outward where no extraction well is located, inducing long travel times.

The solution for the optimized pumping scheme is shown in Figure 15. As one might expect, the most eastern well is shut down, i.e. does not need to be drilled at all which reduces capital costs. Furthermore, the three wells located close to the downstream center line are chosen as extraction wells, whereas the wells outside the initial plume are used for clean water injection, displacing the contaminant toward the extraction wells. As a result, the plume gets concentrated rather than dispersed, leading to a much shorter cleanup time of 294 days, reducing the total costs by more than a factor of two.

\section{Concluding Remarks}

The T2VOC numerical simulator has been linked to the ITOUGH2 code in order to solve groundwater management problems, especially the optimization multi-phase aquifer remediation operations. Three sample problems were discussed in this report, demonstrating the flexibility of prescribing the cost function and choosing the method of its minimization. The cost function represents the part of the management objective that is affected by the hydrological properties of the aquifer, i.e. only those costs are minimized which depend directly or indirectly - on state variables calculated by T2VOC. Consequently, the solution obtained by running the simulation-optimization program has to be critically reviewed by considering technical and economical aspects of the remediation. Nevertheless, the numerical tool used in this study helps investigate alternative cleanup strategies with potentially higher effectiveness and lower cleanup costs. 


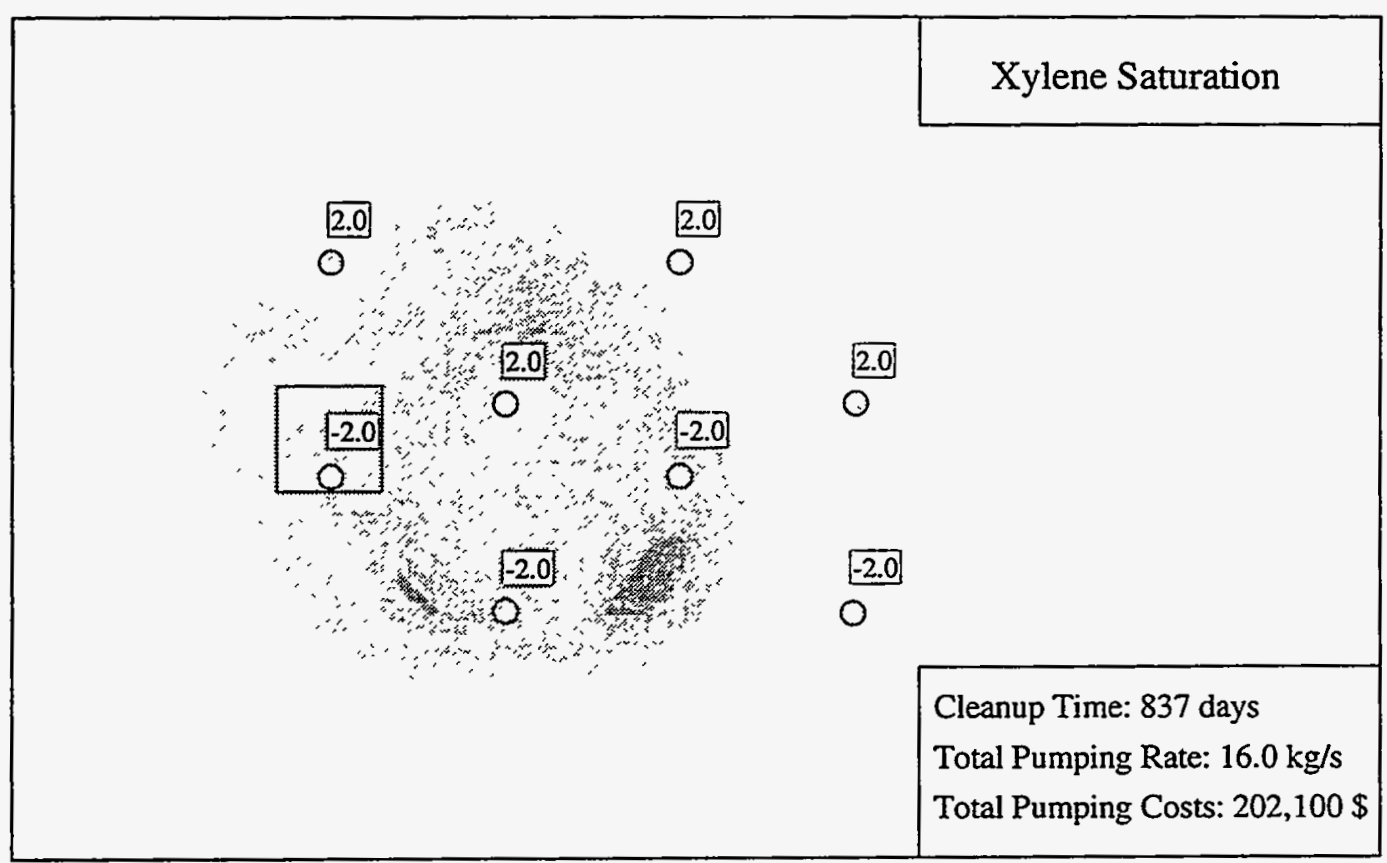

Figure 14: Problem No. 3: NAPL saturation after $60 \%$ of the contaminant mass has been removed, no optimization. Pumping rates are shown in boxes at wells.

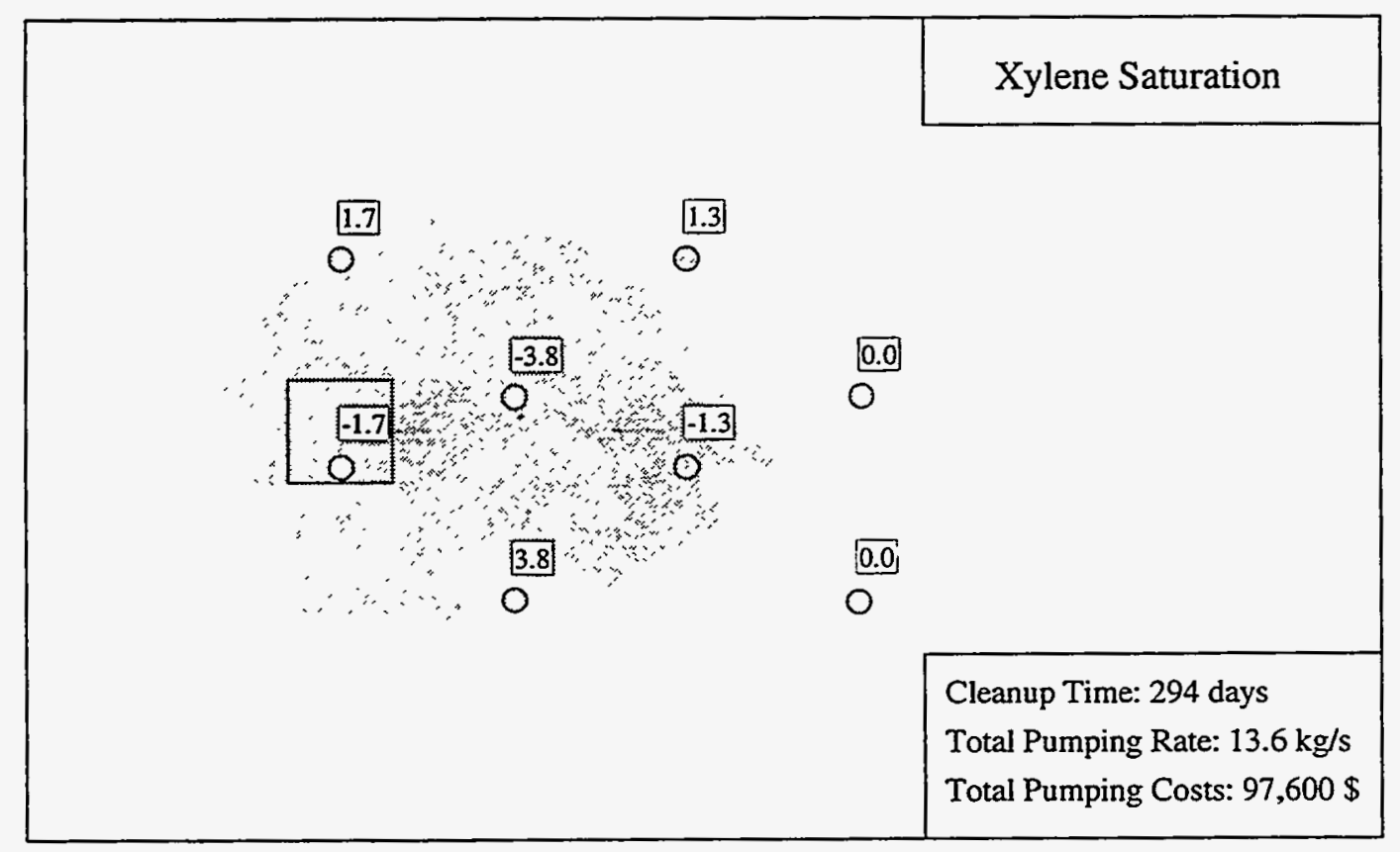

Figure 15: Problem No. 3: NAPL saturation after $60 \%$ of the contaminant mass has been removed, optimized. Pumping rates are shown in boxes at wells. 


\section{ACKNOWLEDGMENT}

This work was supported by the WIPP project, Sandia National Laboratories, under Document No. 129847, and by U.S. Department of Energy, under contract DE-AC0376SF00098. We would like to thank B. Kälin for a helpful discussion of the cost functions. Thanks are due to A. Kovscek, G. J. Moridis, and C. Oldenburg for a careful review of the manuscript.

\section{REFERENCES}

Falta, R. W., and K. Pruess, STMVOC User's Guide, Lawrence Berkeley Laboratory Report LBL-30758, Berkeley, CA, 1991.

Falta, R. W., K. Pruess, I. Javandel, and P. A. Witherspoon, Numerical modeling of steam injection for the removal of nonaqueous phase liquids from the subsurface, 1 . numerical formulation, Water Resour. Res., 28(2), 433-449, 1992.

Falta, R. W., K. Pruess, S. Finsterle, and A. Battistelli, T2VOC User's Guide, Lawrence Berkeley Laboratory Report, Berkeley, CA, draft report October 1994.

Finsterle, S., ITOUGH2 User's Guide, Lawrence Berkeley Laboratory Report LBL-34581, Berkeley, CA, 1993a.

Finsterle, S., and K. Pruess, Solving the Estimation-Identification Problem in Two-Phase Flow Modeling, Lawrence Berkeley Laboratory Report LBL-34581, Berkeley, CA , 1993.

Parker, J. C., R. J. Lenhard, and T. Kuppusamy, A parametric model for sonstitutive properties governing multiphase flow in porous media, Water Resour. Res., 23(4), 4618-624, 1987.

Pruess, K, TOUGH user's guide, Lawrence Berkeley Laboratory Report LBL-20700, Berkeley, CA, 1987.

Pruess, K, TOUGH2 - A general-purpose numerical simulator for multiphase fluid and heat flow, Lawrence Berkeley Laboratory Report LBL-29400, Berkeley, CA, 1991 a.

Stone, H. L., Probability model for estimating three-phase relative permeability, Journal of Petroleum Technology, 22(1), 214-218, 1970. 


\section{APPENdix A: INPUT FILES For SAMPLE Problem No. 1}

\section{A.1 T2VOC Input File For Sample Problem No. 1 (Excerpt)}

This input file was prepared for an earlier version of T2VOC (version 7/93). There are minor differences to the input format described in the current T2VOC User's Guide [Falta et al., 1994].

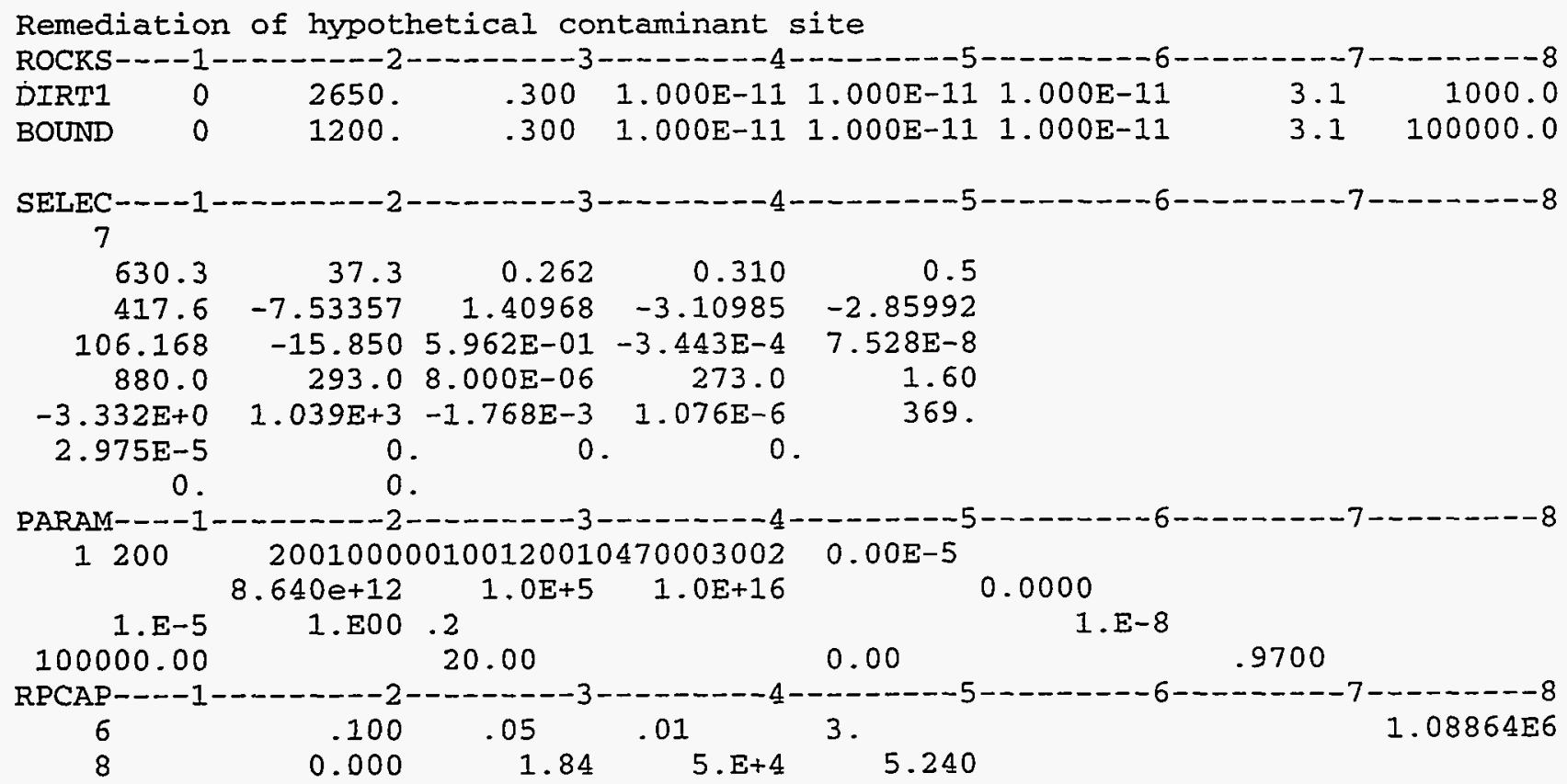

MESHMAKER Mesh is modified to specify boundary condition at $\mathrm{XYZ}$

$\begin{array}{lrl}\text { NX } & 40 & 5.000 E+00 \\ \text { NY } & 25 & 5.0000+00 \\ \text { NZ } & 1 & 1.000 E+01\end{array}$

INCON -- INITIAL CONDITIONS FOR 1000 ELEMENTS ---5-1-

A11 $1 \quad .30000000 E+00.6852 E-11$

$\begin{array}{llll}.1200000000000 E+06 & .2000000000000 E+02 & .0000000000000 E+00 & .9700000000000 E+00\end{array}$

$\ldots \ldots \ldots \ldots \ldots \ldots \ldots$

$\mathrm{A} 1 \mathrm{P} 40 \quad .30000000 \mathrm{E}+00.1422 \mathrm{E}-10$

$\begin{array}{llll}.1000000000000 \mathrm{E}+06 & .2000000000000 \mathrm{E}+02 & .6613155036362 \mathrm{E}-50 \quad .9700000000000 \mathrm{E}+00\end{array}$

$\begin{array}{llll}\text { GENER- } & & \\ \text { A1I10INJ } 1 & \text { MASS } & -2.000 E-00 & 8.393 E+4 \\ \text { A1I20INJ } 2 & \text { MASS }-2.000 E-00 & 8.393 E+4 \\ \text { AID10INJ } 3 & \text { MASS }-2.000 E-00 & 8.393 E+4 \\ \text { A1D15INJ } 4 & \text { MASS }-2.000 E-00 & 8.393 E+4 \\ \text { A1D20INJ } 5 & \text { MASS }-2.000 E-00 & 8.393 E+4 \\ \text { A1810INJ } 6 & \text { MASS }-2.000 E-00 & 8.393 E+4 \\ \text { A1820INJ } 7 & \text { MASS }-2.000 E-00 & 8.393 E+4\end{array}$

ENDCY 


\section{A.2 ITOUGH2 Input File For Sample Problem No. 1}

$>$ PARAMETER

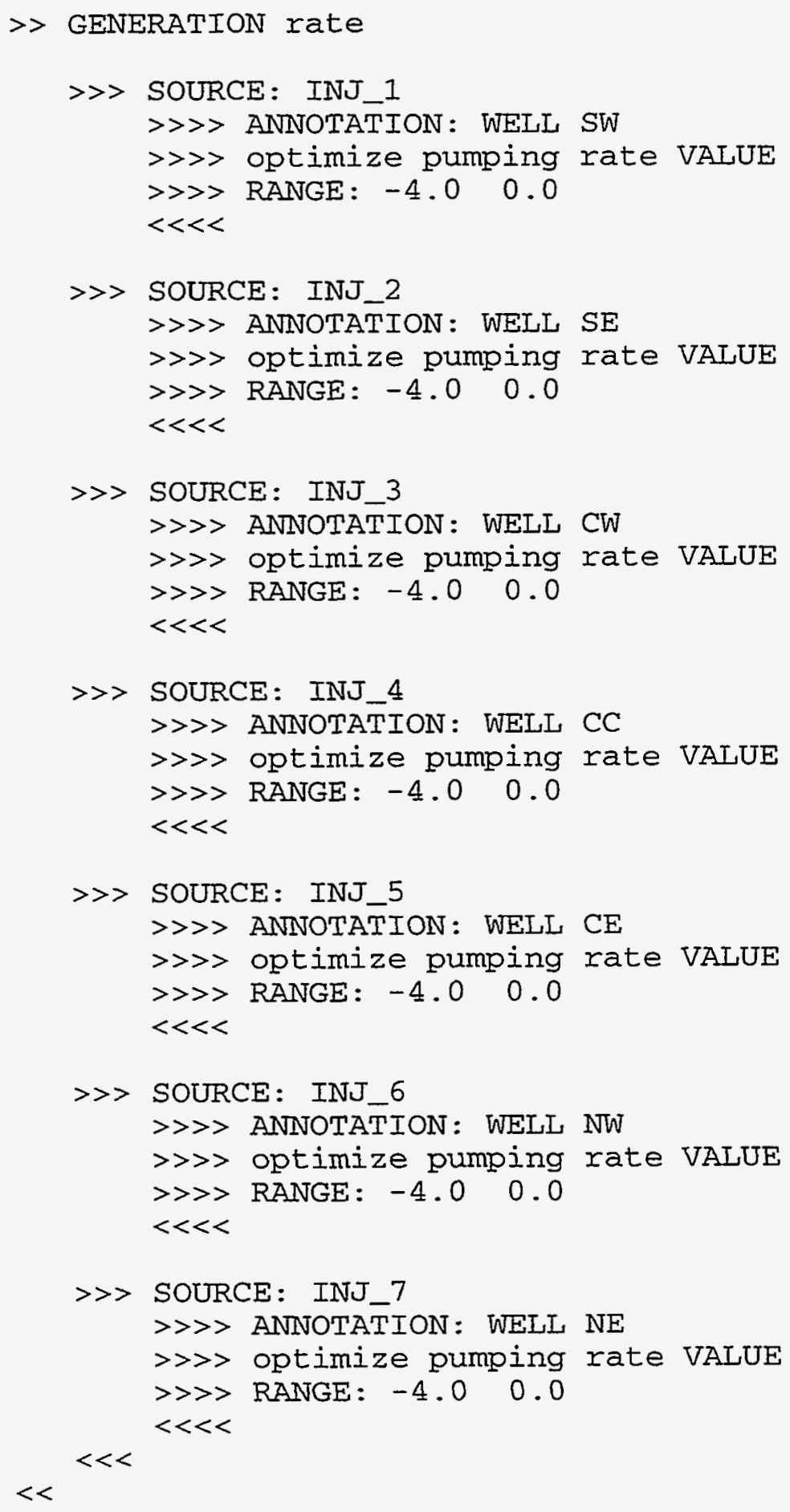


$>$ OBSERVATIONS

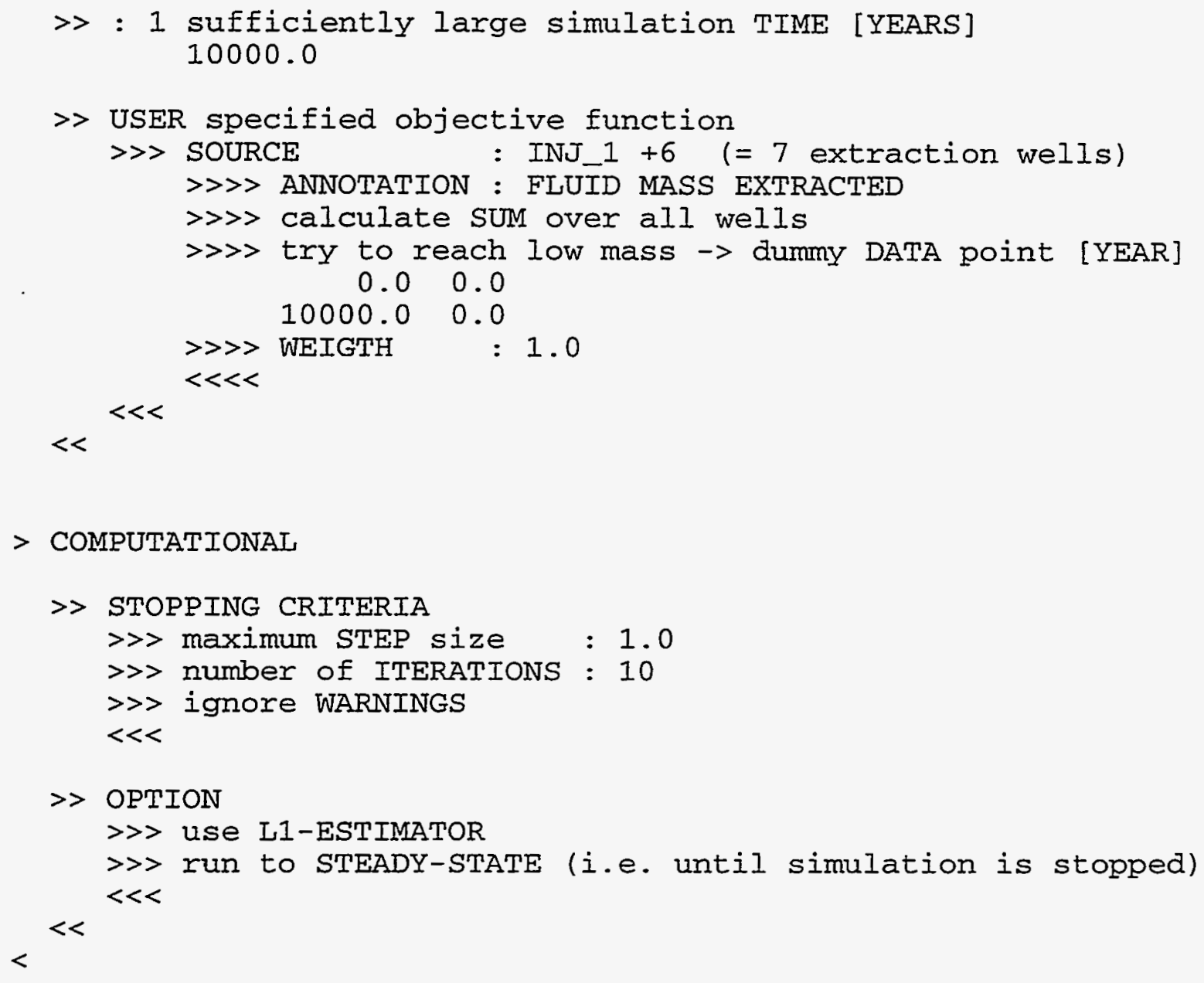




\section{A.3 Subroutine USEROBS For Sample Problem No. 1}

SUBROUTINE USEROBS (IUSER, IOBSA, GRIDA, NECA, INEC, ANNO, TRESULT)

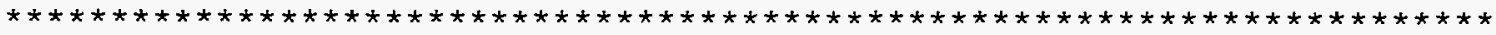

* Subroutine No. 8

* Provides TOUGH2 result for user specified data type

* IUSER : Number of dataset (input)

* IOBSA : Array containing user specified IDs (input)

* GRIDA : Array containing grid block names (input)

* NECA : Array containing index of source, element or connection (i)*

* INEC : Current pointer to GRIDA and NECA, respectively (input)

* ANNO : Annotation (input)

* TRESULT: Provide corresponding TOUGH2 result (output)

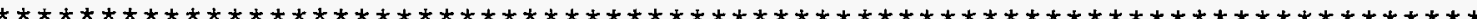

CHARACTER *5 GRIDA, ELEM, ELEM1, ELEM2, SOURCE

CHARACTER * 15 ANNO

C --- TOUGH2 common blocks!

COMMON/CYC/KCYC, ITER, ITERC, TIMIN, SUMTIM, GF , TIMOUT

COMMON/GI6/GPO(1)

DIMENSION GRIDA(*), IOBSA (*), NECA(*)

C --- Calculate total fluid mass being pumped TRESULT $=$ ABS (GPO (INEC) ) * SUMTIM

END

C --- End of USEROBS 


\section{APPENDIX B: ITOUgh2 INPUT File for SAMPLE PRoblem No. 2}

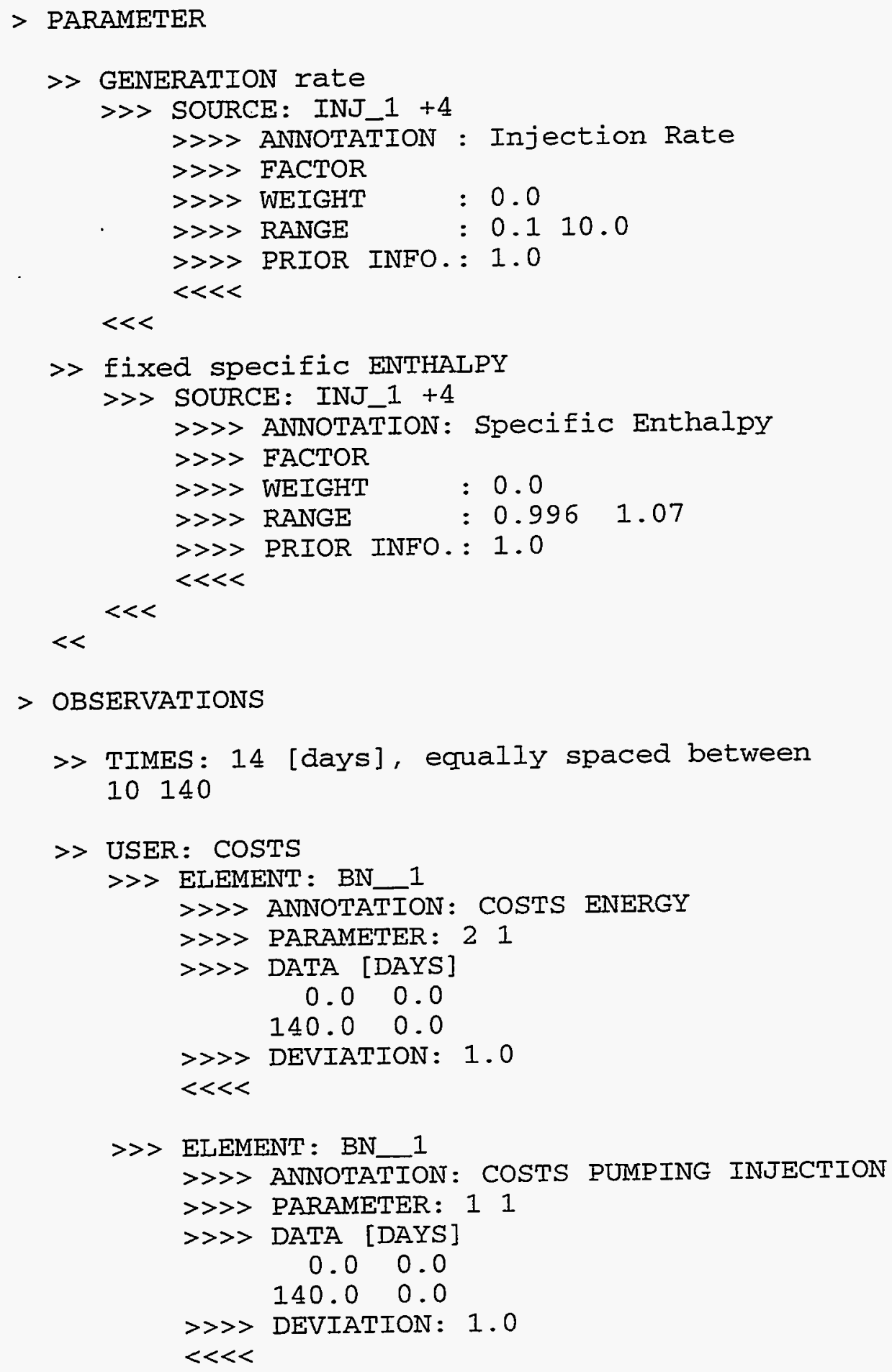




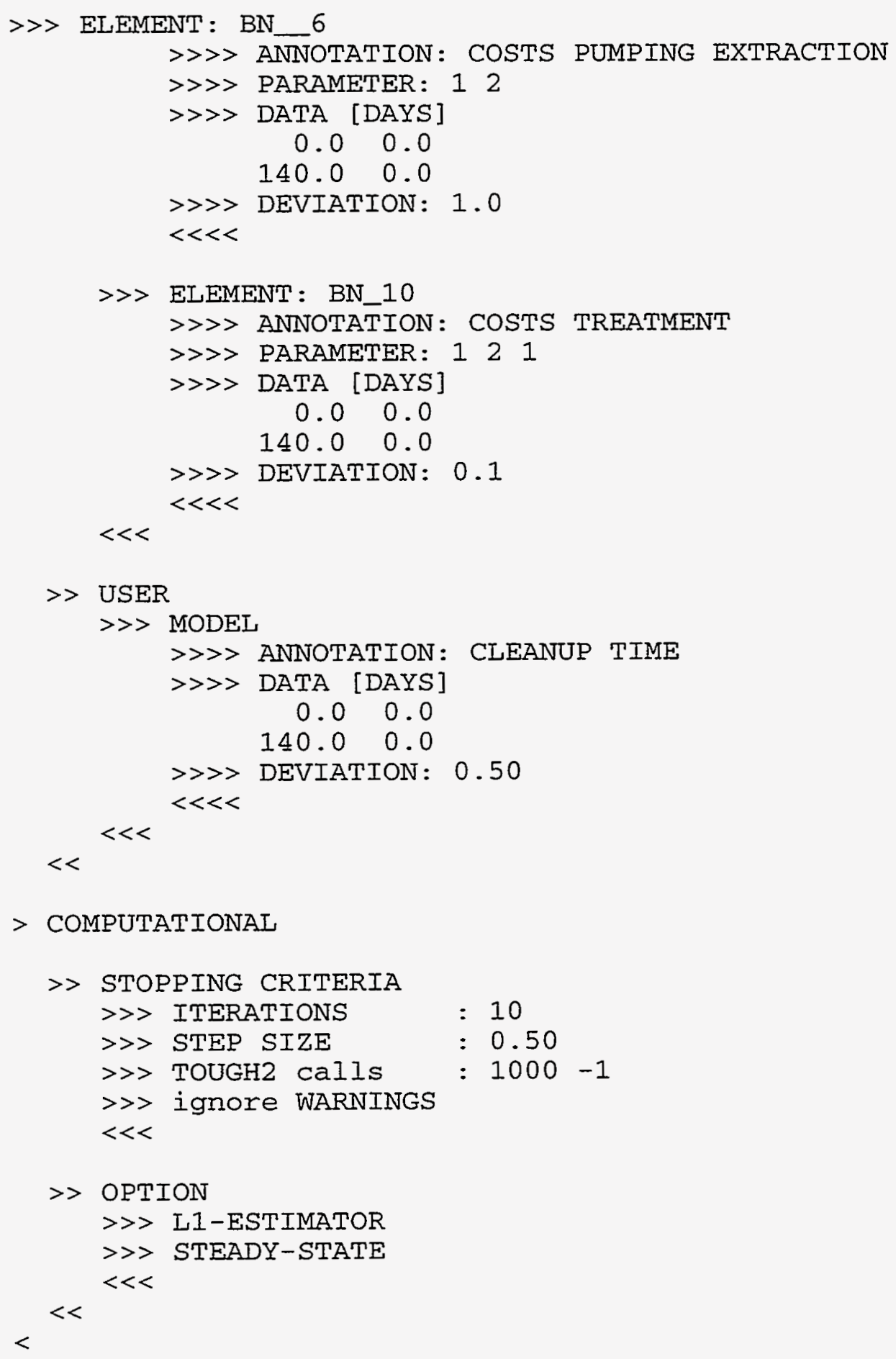


APPENdiX C: INPUT Files for SAMPLE Problem No. 3

C1. ITOUGH2 Input File for Sample Problem No. 3

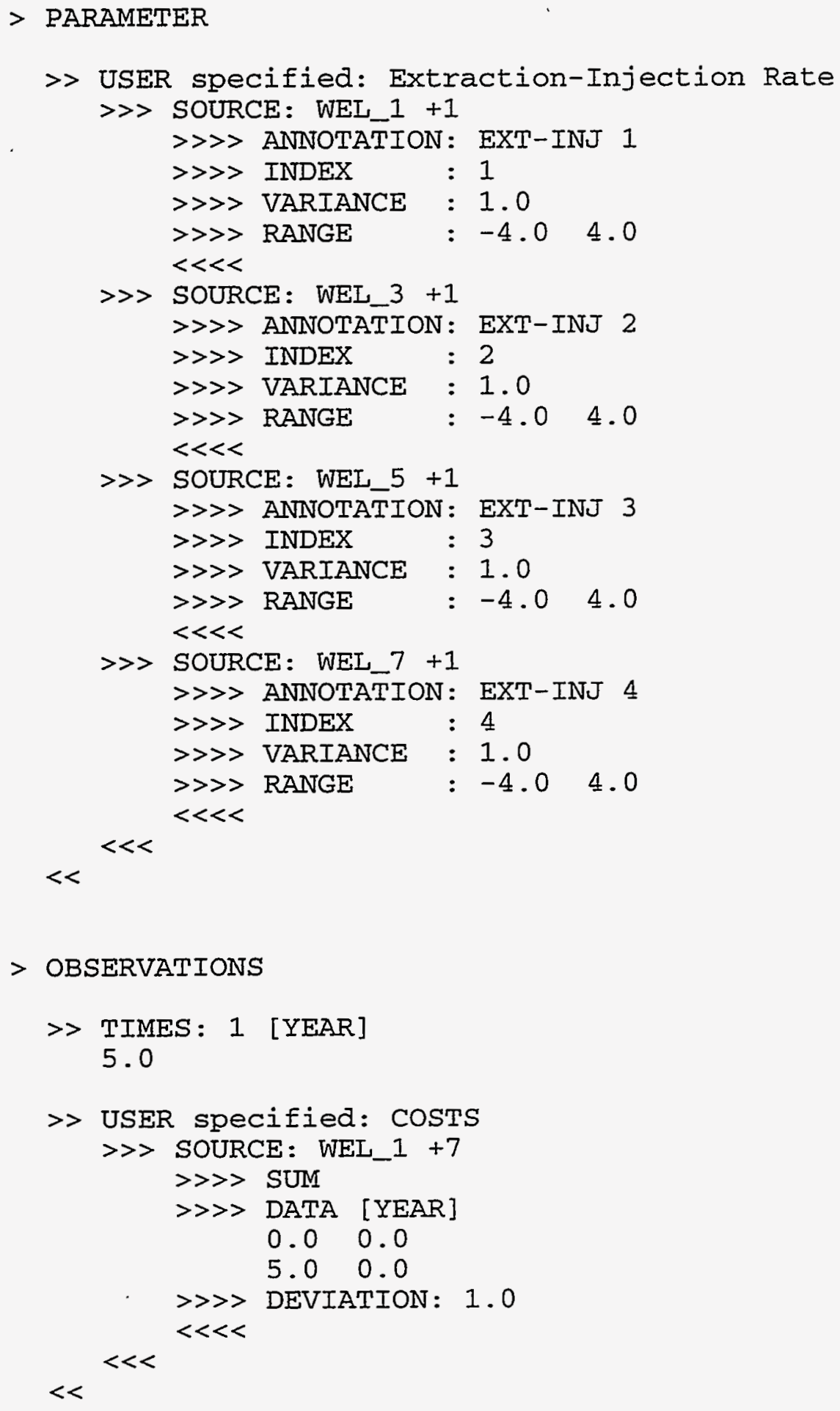


$>$ COMPUTATIONAL

$>$ STOPPING CRITERIA

$>>$ perform: 3 Levenberg-Marquardt ITERATIONS

>> Maximum STEP size: 3.0

$\gg>$ TOUGH2 calls: 10000

$\gg>$ ignore WARNINGS

$<<$

$>>$ OPTION

$>>$ LI-ESTIMATOR

$\gg>$ STEADY-STATE

$>>$ SIMULATED ANNEALING

>>> ITERATIONS : 20

$>>>$ STEPS : 50

$>>>$ TEMPERATURE: -0.05

$\gg>$ SCHEDULE: 0.95

$<<<$

$<<$

$<<$

$<$ 


\section{C2. Subroutine USERPAR for Sample Problem No. 3}

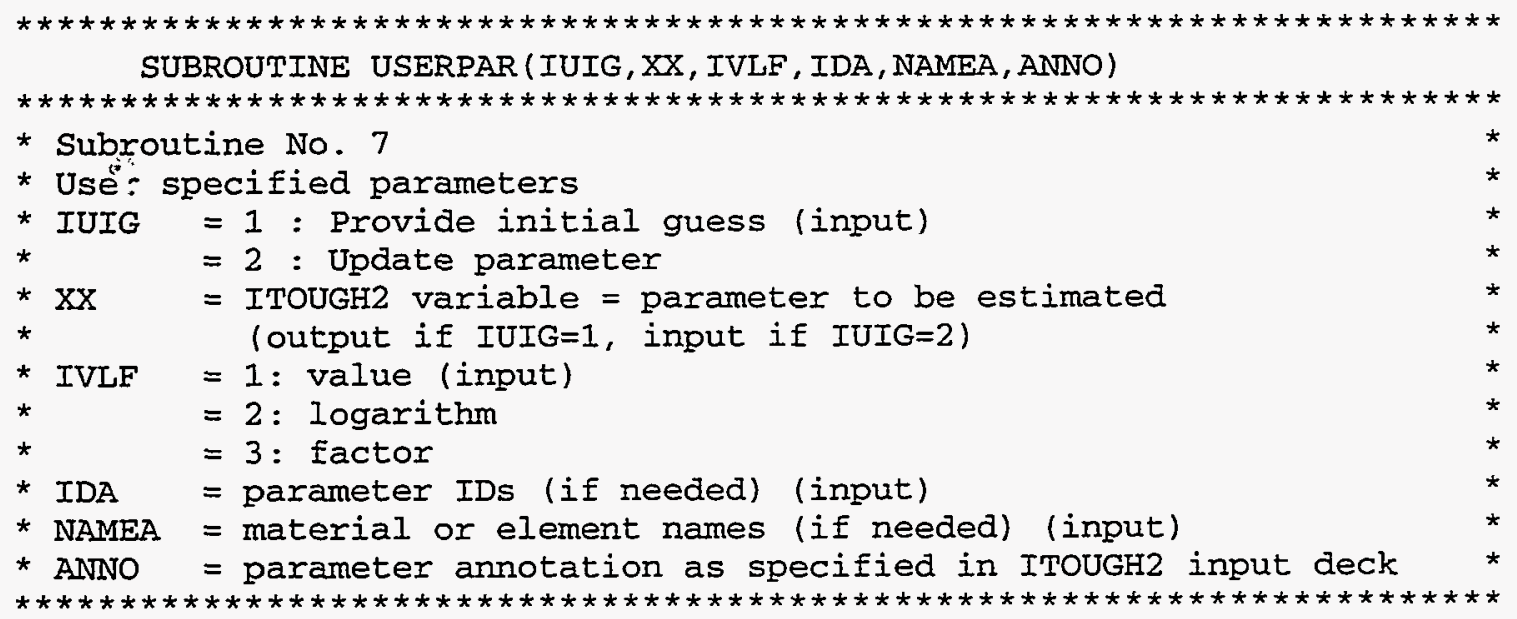

PARAMETER (MINOGN=100)

CHARACTER NAMEA 5, ANNO* 15

DIMENSION NAMEA (*), IDA $\left(^{*}\right)$

C - - ITOUGH2 common block!

COMMON/RATE/GG (MNOGN) , PPI (MNOGN), EEG (MNOGN) , PPWB (MNOGN)

SAVE ICALL

DATA ICALL/O/

$I C A L L=I C A I L+1$

IF (ICALL.EQ.1) WRITE $(11,7999)$

7999 FORMAT (6X, 'USERPAR 2.121 SEPTEMBER 1993',6X,

\& '\# 7 : USER SPECIFIED PARAMETER')

C

C -- Update TOUGH2 parameters

IF (ANNO (1:7) .EQ. 'EXT-INJ') THEN

IS $=(\operatorname{IDA}(1)-1) * 2+1$

IF (ABS $(X X) . L T .0 .2)$ THEN

C --- Shut well down if rate is lower than $0.2 \mathrm{~kg} / \mathrm{s}$

GG (IS) $=0.0$ ELSE $G G(I S+1)=0.0$

C

C --- Assign injection rate $\mathrm{XX}$ $G G(I S)=X X$

C

C -- Assign extraction rate $-\mathrm{XX}$

ENDIF

$\mathrm{GG}($ IS +1$)=-\mathrm{XX}$

ENDIF

END

C --.- End of USERPAR 